\title{
Hyperspectral Geobotanical Remote Sensing for CO2 Storage Monitoring
}

\author{
W.L. Pickles, W.A. Cover
}

This article was submitted to The $\mathrm{CO} 2$ Capture and Storage Project for Carbon Dioxide Storage in Deep Geological Formations for Climate Change Mitigation

\section{May 1, 2004}

U.S. Department of Enargy

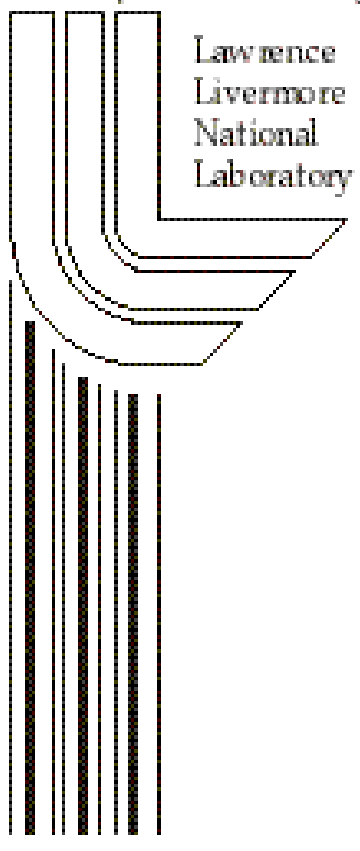




\section{DISCLAIMER}

This document was prepared as an account of work sponsored by an agency of the United States Government. Neither the United States Government nor the University of California nor any of their employees, makes any warranty, express or implied, or assumes any legal liability or responsibility for the accuracy, completeness, or usefulness of any information, apparatus, product, or process disclosed, or represents that its use would not infringe privately owned rights. Reference herein to any specific commercial product, process, or service by trade name, trademark, manufacturer, or otherwise, does not necessarily constitute or imply its endorsement, recommendation, or favoring by the United States Government or the University of California. The views and opinions of authors expressed herein do not necessarily state or reflect those of the United States Government or the University of California, and shall not be used for advertising or product endorsement purposes.

This is a preprint of a paper intended for publication in a journal or proceedings. Since changes may be made before publication, this preprint is made available with the understanding that it will not be cited or reproduced without the permission of the author. 


\title{
Hyperspectral Geobotanical Remote Sensing for CO2 Storage Monitoring
}

\author{
Dr William L. Pickles, LLNL, Ms Wendy A. Cover, UCSC
}

\begin{abstract}
This project's goal is to develop remote sensing methods for early detection and spatial mapping, over whole regions simultaneously, of any surface areas under which there are significant $\mathrm{CO} 2$ leaks from deep underground storage formations. If large amounts of $\mathrm{CO} 2$ gas percolated up from a storage formation below to within plant root depth of the surface, the $\mathrm{CO} 2$ soil concentrations near the surface would become elevated and would affect individual plants and their local plant ecologies. Excessive soil $\mathrm{CO} 2$ concentrations are observed to significantly affect local plant and animal ecologies in our geothermal exploration, remote sensing research program at Mammoth Mountain CA USA. We also know from our geothermal exploration remote sensing programs, that we can map subtle hidden faults by spatial signatures of altered minerals and of plant species and health distributions. Mapping hidden faults is important because in our experience these highly localized (one to several centimeters) spatial pathways are good candidates for potentially significant $\mathrm{CO} 2$ leaks from deep underground formations. The detection and discrimination method we are developing uses primarily airborne hyperspectral, high spatial (3 meter) with 128 band wavelength resolution, visible and near infrared reflected light imagery. We also are using the newly available "Quickbird" satellite imagery that has high spatial resolution (0.6 meter for panchromatic images, 2.4 meters for multispectral). We have a commercial provider, HyVista Corp of Sydney Australia, of airborne hyperspectral imagery acquisitions and very relevant image data post processing, so that eventually the ongoing surveillance of $\mathrm{CO} 2$ storage fields can be contracted for commercially. This research project is a collaboration between two University of California campuses, Lawrence Livermore National Laboratory (LLNL) and UC Santa Cruz (UCSC) and HyVista Corp in Sydney Australia. The collaboration participation is large and involves the newly created Center for Remote Sensing at UC Santa Cruz. A physicist/Senior Scientist at LLNL, William L. (Bill) Pickles, two UC Santa Cruz Professors, Eli Silver, Geology, and Don Potts, Biology, a Ph. D. graduate student, Wendy A. Cover, a Masters degree graduate student Ty Kennedy-Bowdoin and our recently graduated PH. D student, Dr. Brigette A. Martini have all worked on this CO2 monitoring and surveillance project. We have also collaborated with Ron Klusman at Colorado School of Mines who has measured $\mathrm{CO} 2$ and methane soil concentrations at many locations in the Rangely Colorado oil field, which is our study site for this project. In this project we have imaged the Rangely Colorado Oil field and surrounding areas with an airborne hyperspectral visible and near infrared reflected light sensor. The images were analyzed by several methods using the suite of tools available in the ENVI commercial hyperspectral image processing software. We have also begun to use the high resolution (0.6 meter) commercial satellite QuickBird in our technology development.

This hyperspectral imaging project for $\mathrm{CO} 2$ leakage monitoring has focused on using the extensive hyperspectral imagery set that we acquired of the Rangely $\mathrm{CO}$ enhanced oil recovery field in August 2002. We have accomplished extensive analysis of this imagery. We have created highly detailed maps of soil types, plant coverages, plant health, local ecologies or habitats, water conditions, and manmade objects throughout the entire Rangely Oil field and surrounding areas. The results were verified during a field trip to Rangely CO in August 2003. These maps establish an environmental and ecological baseline against which any future $\mathrm{CO} 2$ leakage effects on the plants, plant habitats, soils and water conditions can be detected and verified. We have also seen signatures that may be subtle hidden faults. If confirmed these faults might provide pathways for upward $\mathrm{CO} 2$ migration if that occurred at any time during the future.
\end{abstract}

We have found a result that was unexpected, new to us, and potentially very important to the task of monitoring for $\mathrm{CO} 2$ that has leaked to within the plant root depths near the surface. The discovery is that one of our analysis techniques has picked out finely detailed mapping of local ecologies. Some of which are found to extend across the entire Rangely oil field and into the 
surrounding areas. These ecologies appear to be made up of a fairly narrow range of percentage admixtures of two or three very specific plant types and soil types. It is likely that any large amounts of $\mathrm{CO} 2$ reaching the root depth near the surface would begin to modify the shapes of the habitats. These habitat changes will be easy to detect by repeat imaging of the area. The habitat modification signature is probably detectable earlier following the start of $\mathrm{CO} 2$ build up in the soil, than looking for individual plant stress.

We strongly recommend a long term research effort that will establish what $\mathrm{CO} 2$ soil concentration levels produce observable changes in the biosphere and the corresponding subtle and complex ecological distributions in various environments (including terrestrial and marine). This is an extremely important and highly relevant task for CCP SMV to pursue in our opinion.

\section{Introduction}

The purpose of this research program has been to develop remote sensing methods that can detect and discriminate the effects of elevated soil $\mathrm{CO} 2$ concentrations on the local plants, their local habitats or ecologies, and to map possible hidden faulting systems at the surface above underground geological $\mathrm{CO} 2$ storage formations. This research program was inspired by the results from our DOE geothermal remote sensing exploration research programs done at Mammoth Mountain California, USA. In this work, we were able to map areas of tree kills and surrounding regions of plant stress, due to elevated $\mathrm{CO} 2$ soil concentration levels caused by $\mathrm{CO} 2$ effluents from the magma below the mountain.

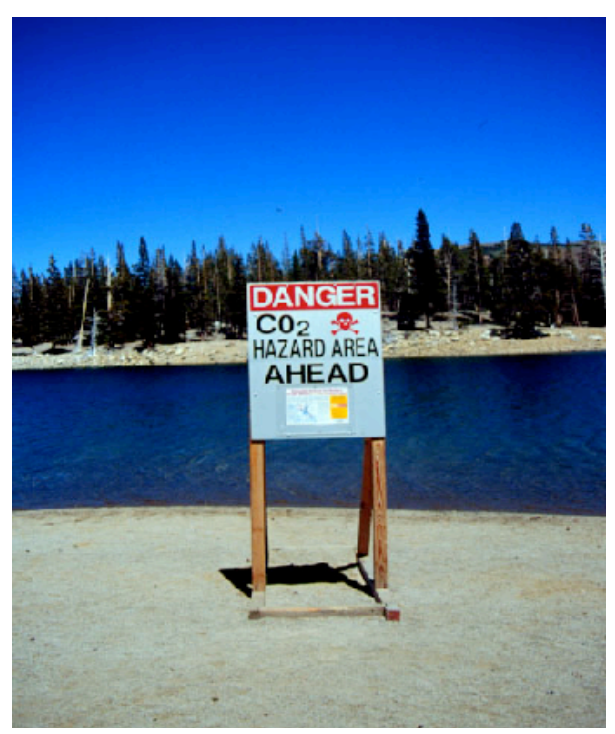

Figure 1 At Mammoth Mountain CO2 Emission levels burst on short time scales to hazardous levels in small areas

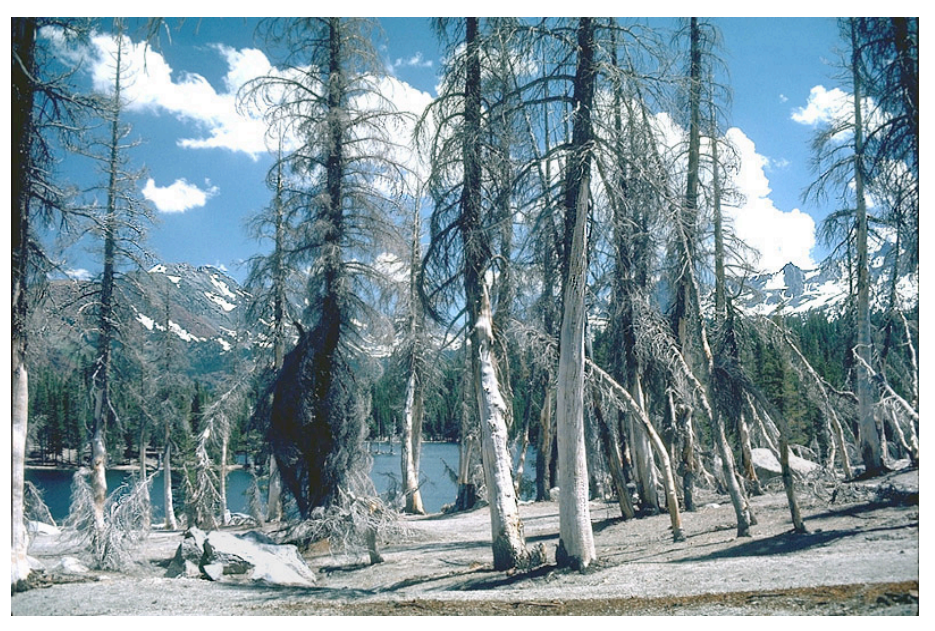

Figure 2 Trees killed at Mammoth Mountain CA by highly elevated $\mathrm{CO} 2$ soil concentrations. This area is near Horseshow Lake 


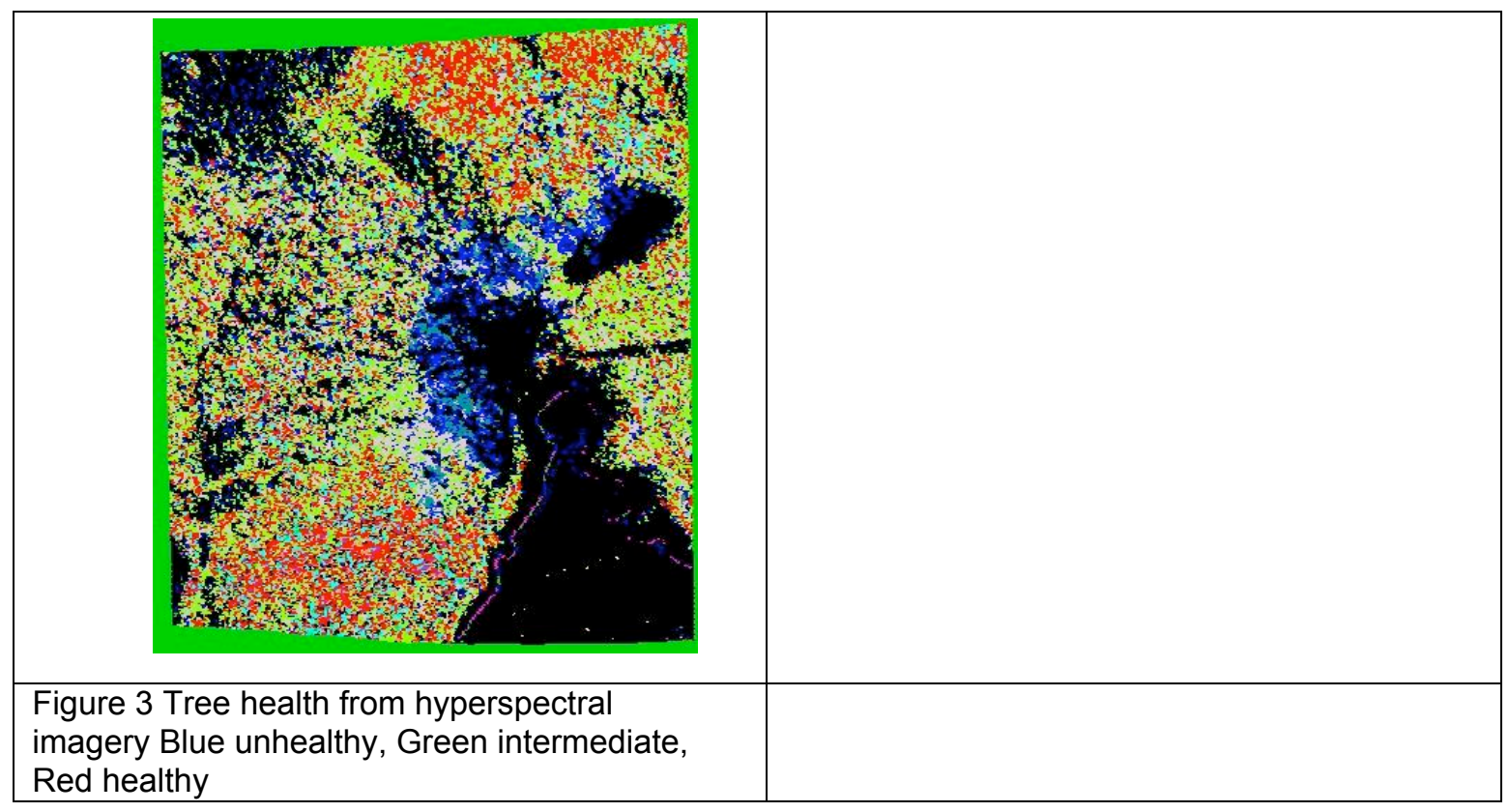




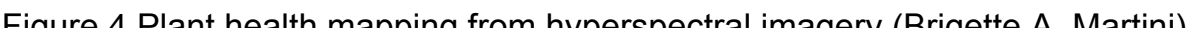

$119^{\circ} 1^{\prime} 48^{\prime \prime} W$

$119^{\circ} 1 ' 30^{\prime \prime W}$

$119^{\circ} 1^{\prime} 12^{\prime \prime W}$

$119^{\circ} 0^{\prime} 54^{\prime \prime} W$

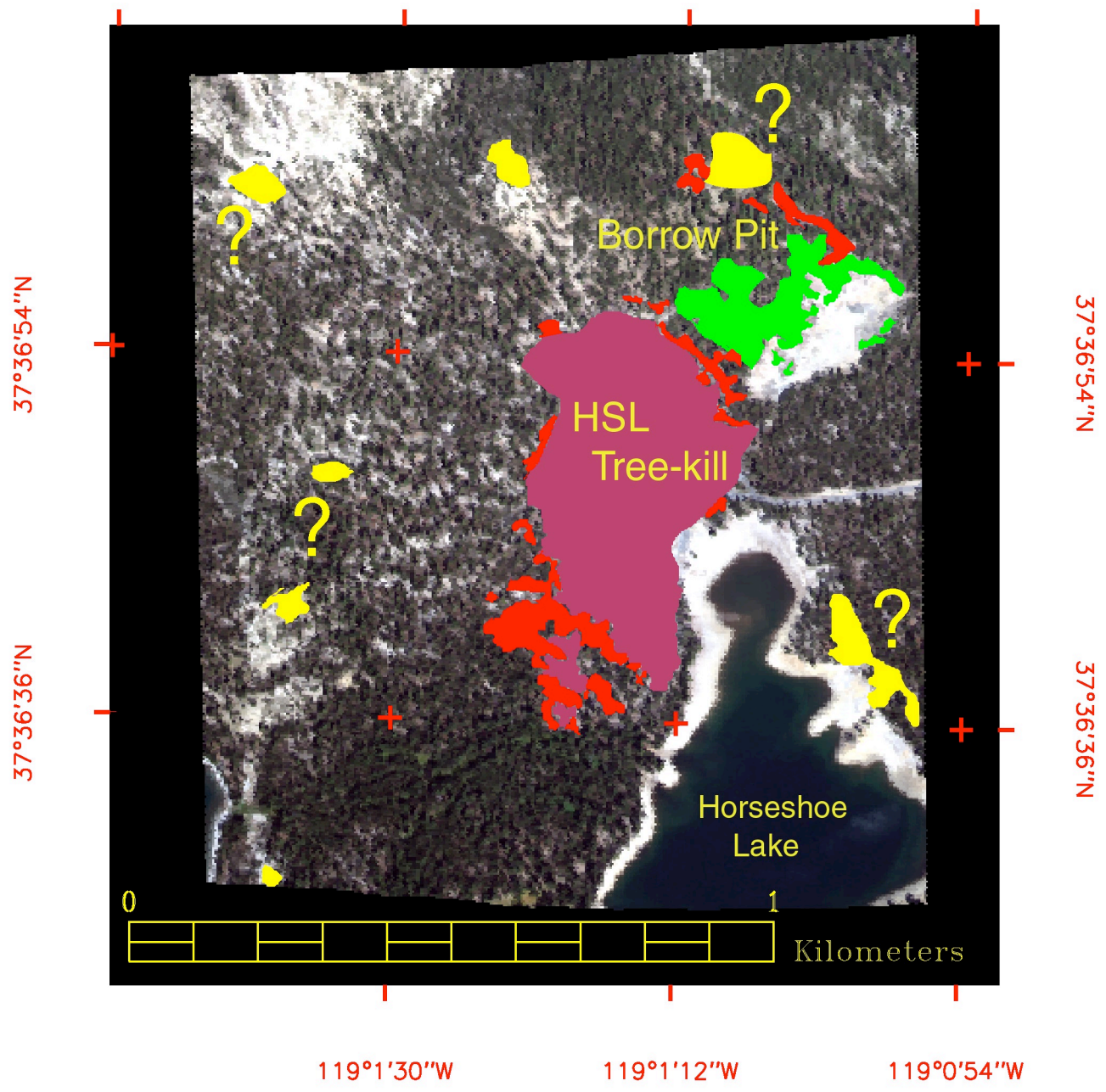


The locating of hidden faults using the hyperspectral imagery is also inspired by Brigette's hidden fault discovery using hyperspectral imagery at Mammoth Mountain CA and at Dixie Valley NV, USA. See the first six references. In Brigette Martini's thesis, you will see that she found new subtle hidden faults by mapping mineralization and plant signature shifts. This is important for $\mathrm{CO} 2$ sequestration because we feel that if $\mathrm{CO} 2$ were escaping from an underground storage formation it would probably convect along cracks, joints, and faults if there were any.

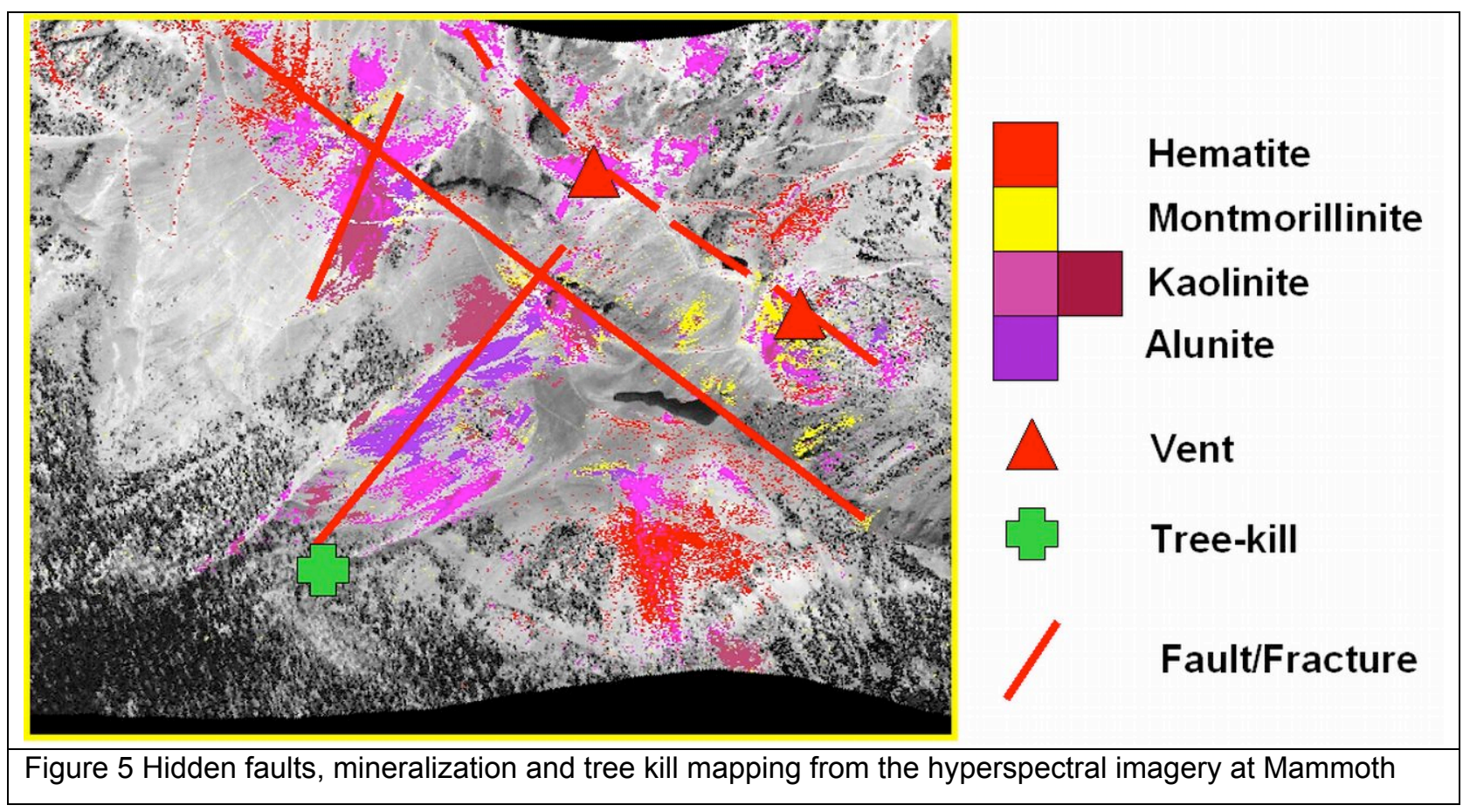

The localization of $\mathrm{CO} 2$ effluent is supported by John Rogie's hand held $\mathrm{CO} 2$ measurements at Mammoth that he has made just above the ground in the air. He very found very high spatial variability like a few feet. In addition, he and Mike Sorey, who were then at USGS Menlo Park presented a very revealing paper at the AGU in Dec in San Francisco a few years back. They showed their year long measured $\mathrm{CO} 2$ effluent variations at individual locations at Mammoth. Their data showed highly variable effluent rates, with factors of 10 to 50 not uncommon. They also converted their measurements to a frequency distribution, which is change of $\mathrm{CO} 2$ concentration per hour at a fixed location. The distribution was in fact primarily high frequency components, i.e. hourly and daily changes! This is an important observation. They also observed the $\mathrm{CO} 2$ flux was correlated with the barometric pressure, not anti correlated as you would expect from "pumping". Normally gas effluent increases from soils, marshes, garbage dumps, buried solvent contaminated dumpsites, etc. when the barometric pressure falls, then decreases when the pressure rises. Mammoth behaves in the reverse! They also saw a wind speed correlation.

From our geothermal exploration research at Mammoth Mountain, we do understand some of the issues about how $\mathrm{CO} 2$ soil concentrations would behave if $\mathrm{CO} 2$ leakage from an underground storage formation started rising to within root depth of the surface. A number of researchers feel that the plant effects seen at Mammoth are related to suffocation of the roots not from $\mathrm{PH}$ changes, although we are not sure if that is completely true. Ref Martini Thesis Chapter 3

In this CCP SMV research program we are extending these techniques and experience to study an Enhanced Oil Recovery (EOR) Field at Rangely Colorado USA. The field has been injected with $\mathrm{CO} 2$ for 15 years to enhance oil recovery. We acquired airborne hyperspectral imagery of the Rangely Oil Field, the surrounding areas including the town of Rangely CO in August 2002. 
We have made two extensive field trips to Rangely, one in August 2002 and then returning with the analysis of the imagery in August 2003.

In our study of the plant life at Rangely Co oil field and surrounding areas on the second field trip in August 2003, we did not observe any plant life effects that might be due to CO2 effluents. There are some $\mathrm{CO} 2$ and methane soil concentrations at about a dozen sampling locations in the area that are elevated above normal levels. Ron Klusman, who is at the Colorado School of Mines in Golden CO, USA made these measurements as part of a DOE funded project to study $\mathrm{CO} 2$ and methane concentrations in soils and in the air at the Rangely oil field. He has produced a final report. The elevated readings he observed were as much as 100 times the natural CO2 concentrations caused by the activities of the microorganisms in the soil. He found winter to summer variations. He also did isotopics on the $\mathrm{CO} 2$ and Methane at many locations. These measurements were made over several years. The soil concentration levels that Ron measured do not affect the "plant health" noticeably with any measurements we made, in the imagery and on the ground using the field portable spectroradiometer this summer. What we did discover during our fieldwork at Rangely this summer is that the hyperspectral imagery of this relative dry high dessert area maps the complex spatial distributions of a number of subtlety different "habitats". We suspicion that if $\mathrm{CO} 2$ soil concentrations were to start rising "significantly" above normal levels in well-defined spatial zones that the habitats in that area might shift distributions. We would of course see that easily and can provide a mapping of all those changes over time.

A missing piece of the puzzle is what are the "significant" levels of $\mathrm{CO} 2$ soil concentration that would begin to affect plant health, or the shape and types of local ecologies or habitats. What effects do time dependent and spatially dependent $\mathrm{CO} 2$ effluent variations play? Probably a lot. What are the characteristic time scales that are relevant?

There is also the issue of concentrations of $\mathrm{CO} 2$ in the air that are problems for many of the ground dwelling animals in the area. At Mammoth as you can see in Brigette's publications, there are very highly localized $\mathrm{CO} 2$ concentrations that can kill animals and have killed some humans. Buildings in the Mammoth area have $\mathrm{CO} 2$ alarms in confined spaces.

The hyperspectral geobotanical remote sensing techniques that we are developing use advanced commercial airborne imaging spectrometer systems now available in the USA and worldwide. The sensor system we normally contract for in our overhead imaging missions, produces visible and near IR reflected light images with spatial resolution of 1 to 3 meters in 128 wavelength bands. Please see http://www.hyvista.com/

The extraordinary HyVista sensor spatial and wavelength imagery resolution and signal to noise ratio of over 1000 to 1 allows us to detect and discriminate individual species of plants as well as the complexities of the geological and man made objects in the images. Apparently based on our new results we can also discriminate subtle local plant ecologies in incredible and verifiable detail.

We can then look for biological impacts of $\mathrm{CO}_{2}$ leaks or seepages in large complicated areas such as estuaries, ports, rivers, deserts, forests, grasslands, farmlands, cities, industrial areas, etc. These techniques do not require before and after imagery because they use the spatial patterns of plant species and health variations present in the one image to distinguish slow leaks.

These techniques should allow us to distinguish the effects of small leaks from the damage caused to the biosphere by the other local human activities such as pipeline construction and natural factors such as storm run off. The plants in an area can accumulate small doses of leaked materials. The plant health and species modification spatial patterns do record timeintegrated effects of small quantities of leaked $\mathrm{CO}_{2}$. This can be important in finding leaks that would other wise are hard or impossible to detect by direct observation of soil $\mathrm{CO} 2$ concentrations. 


\section{Experimental / Study Methodology}

The experimental method we have used is summarized in the following series of sequentially executed steps.

Determine the area above the formation to be monitored including some surrounding areas that are thought to be outside the influence of any $\mathrm{CO} 2$ that might percolate to the surface.

Work with the airborne hyperspectral image acquisition contractor to develop a set of flight lines along which the images will be acquired.

If possible make a group trip to the area to start to become familiar with the special characteristics of the region at the time planned for the airborne overhead image acquisition.

Using GPS (Garmin 76 handheld with mapping) and digital cameras (Canon G2) visually record the soils, plants, minerals, waters, and manmade objects in the area.

Remain on location to be available to the pilots and image sensor operator while the imagery is being acquired. This is usually one day between 10:00 and 14:00. But it can be two days. We normally all meet at the aircraft before and after the day's flight to go over the plans and check results.

After the acquisition is completed our team reviews the imagery and georectification at the plane or in a motel. Our acquisition contractor then sends it to their main facility Sydney Australia for final post processing.

The imagery set of all flight lines is returned to us on DVD's as three products; Raw, corrected to reflectance including atmospheric absorptions, and georectification control files. This usually takes less than a few weeks.

The imagery on the DVD's is analyzed using the ENVI commercial computer software on Windows and or UNIX platforms, by our researchers at UCSC, LLNL, and HyVista Corp, working as team. Please see the Research Systems Inc web site at http://www.rsinc.com/envi/index.asp for information about the ENVI program. Joe Boardman http://www.aigllc.com/ and Fred Kruse http://www.hgimaging.com/ wrote the ENVI program and help us in dealing with its complexities. ENVI is considered the standard for the hyperspectral image analysis community worldwide. We then use ENVI to analyze the imagery. We use several different routines available within the ENVI program suite to produce "maps" of plant species types, plant health within species types, soil types, soil conditions, water bodies, water contents such as algae or sediments, mineralogy of exposed formations, and manmade objects such as roads, buildings, playgrounds, golf courses, and we have discovered in this research project that we can map distinct "ecologies". These "maps" are actually collections of individual georectified pixels.

The maps derived from the imagery analysis are the studied to look for species of plants where they would normally not be found, relative plant health patterns, altered mineral distributions, soil type distributions soil moisture distributions, water and water contents, and other categories. We then return to the field with our analysis available in our laptop computers running ENVI to verify and further understand the complex mappings produced. Based on the verification results the analysis can be "fine-tuned" in the field to produce more accurate maps. Since the maps are georectified and the pixel size is 3 meters individual objects such as trees, outcropping minerals, jeep trails, well heads and pads can all be located using the maps and handheld a GPS. So the verified maps are extremely accurate. We also use a backpackable field specroradiometer to measure reflectance spectra from a large number of plants, soils and minerals. Figure 6 shows Wendy Cover using the ASD spectroradiomiter at Rangely during our second field trip in August 2003. The spectrometer is in the backpack. The computer that controls the spectrometer and displays the acquired spectra is in a front pack sling. The pistol grip lens that is connected to the spectrometer by a fiber optic cable, is in her right hand, 


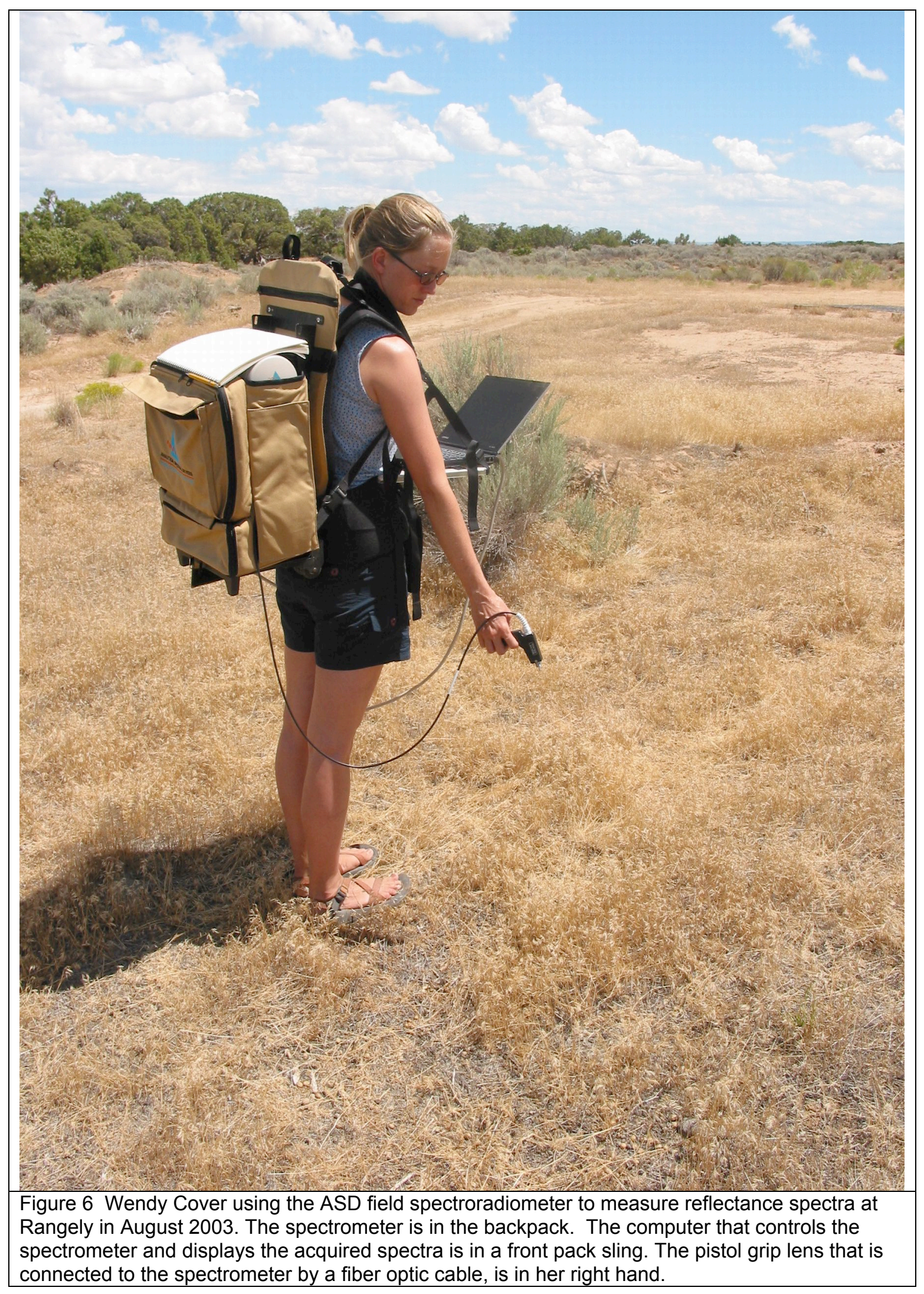


These detailed maps then form a snapshot of the conditions of the biosphere at the time of acquisition. They would show any areas of existing anomalous conditions such as plant kills and linear species modifications caused by hidden faults. They are also the "baseline" that is used to chart any future changes that are not due simply to normal seasonal and weather variations. This is accomplished by reimaging the area routinely over the years to monitor and document any effects that would be caused by significant $\mathrm{CO} 2$ leakage reaching the surface and near subsurface defined by the root depth of the local plants.

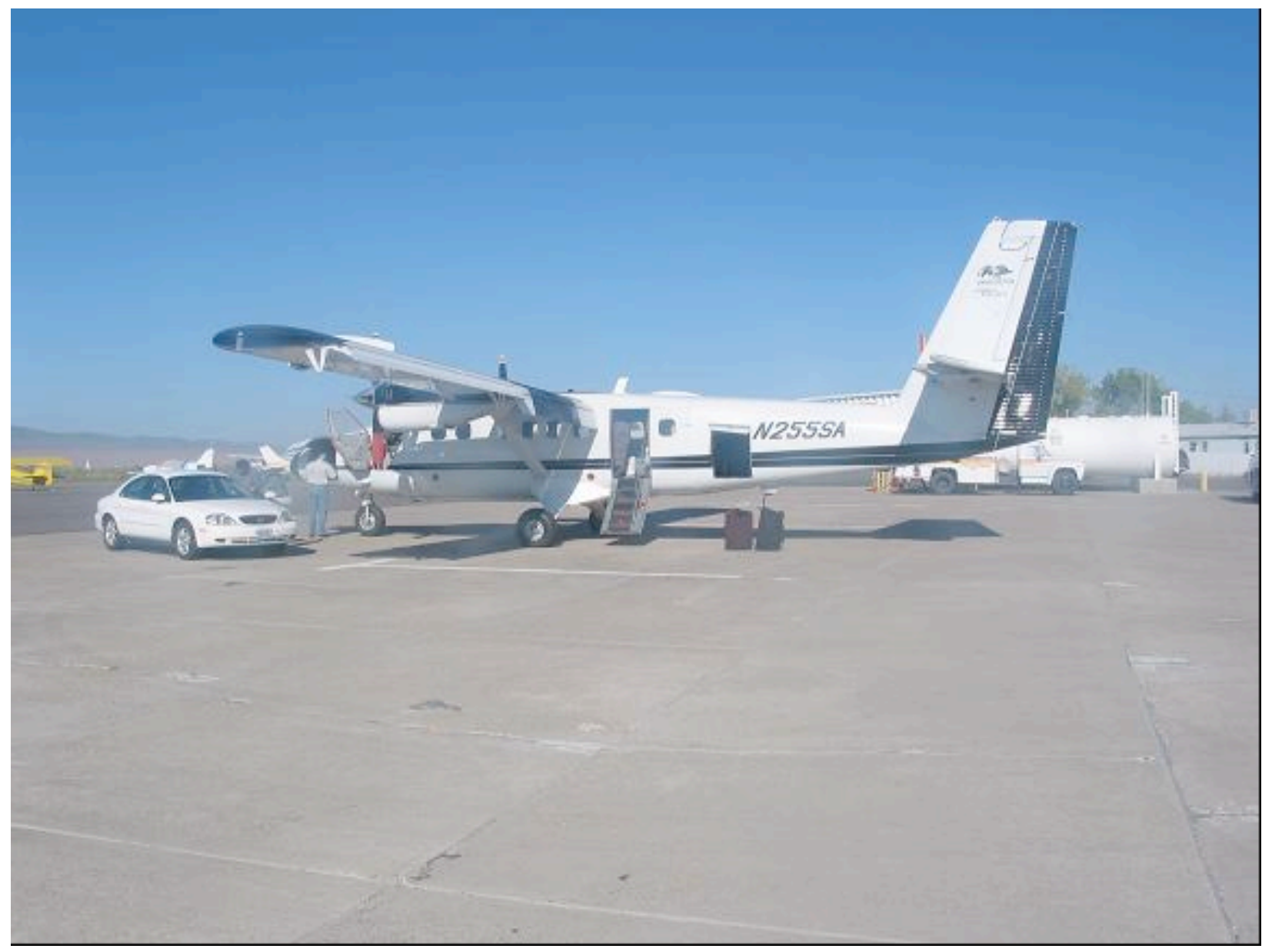

Figure 7 Morning preparations of the B 300 Twin Otter aircraft rented by HyVista. The LLNL UCSC team meets with the HyVista team while they are preparing the Hymap sensor, the georectification system, and computer system for the hyperspectral image acquisition. Note the clear skies, which is ideal

The sensor used for the image acquisition at Rangely Colorado is the HyMap ${ }^{\mathrm{TM}}$ hyperspectral scanner manufactured by Integrated Spectronics Pty Ltd. The HyMap sensor provides 126 bands across the reflective solar wavelength region of $0.45-2.5 \mathrm{~nm}$ with contiguous spectral coverage (except in the atmospheric water vapor bands) and bandwidths between $15-20 \mathrm{~nm}$. 
The sensor operates on a 3-axis gyro-stabilized platform to minimize image distortion due to aircraft motion. The Hymap sensor provides a signal to noise ratio $(>500: 1)$. Laboratory calibration and then daily operational system monitoring is done by HyVista to ensure that the calibration of the imagery is stable which is required for our very demanding spectral mapping tasks. Geolocation and image geocoding is achieved with an-on board Differential GPS (DGPS) and an integrated IMU (inertial monitoring unit). Typically the HyMap sensor is operated with an angular field of view (IFOV) of $2.5 \mathrm{mr}$ (mili-radians) along track, $2.0 \mathrm{mr}$ across track, Field of view (FOV) of 61.3 degrees (512 pixels), Differential GPS (DGPS) and an integrated IMU (inertial monitoring unit), GIFOV - 3-10 m (typical operational range) The DGPS and IMU is fully integrated with the image acquisition. The latitude and longitude of each pixel is recorded along with the hyperspectral image. We are finding that the accuracy of this method is about one or two pixels over flat ground. This is phenomenal geolocation of the raw imagery. This is central in developing our methodology because it means we can analyze the imagery data in any series of complex we find most useful and then we convert the final product to a highly accurate georectified form that can be verified and studied in the field. The georectification subroutine is built into the ENVI software. It uses the georectification data files (GLT files) recorded in the airplane.

The sensor characteristics and a discussion of overhead hyperspectral imagery acquisition can be studied further at the web site of our imagery acquisition contractor. http://www.hyvista.com/ and at http://www.intspec.com/

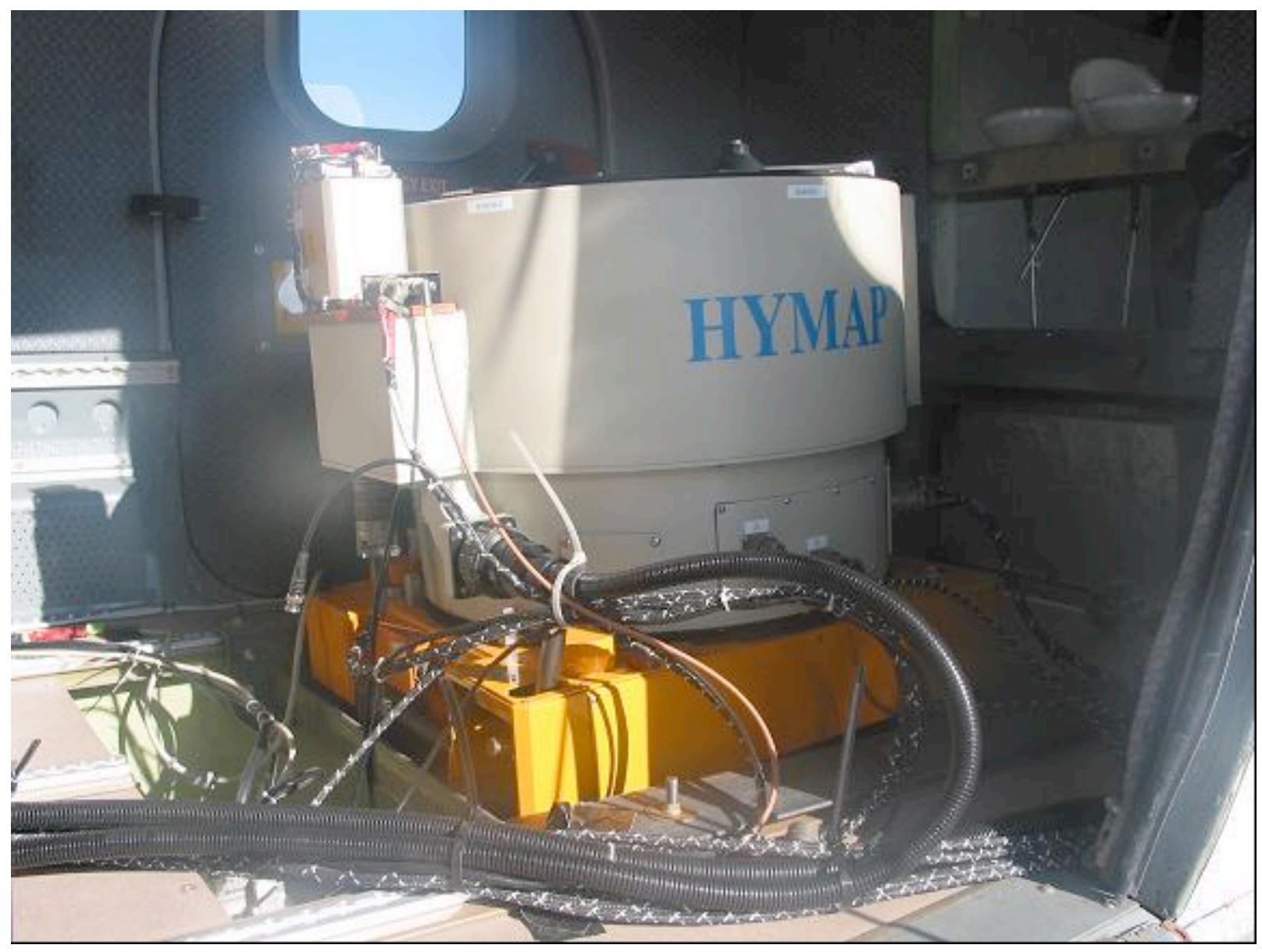

Figure 8. The hyperspectral sensor is shown in the aircraft used by our acquisition contractor for image acquisitions. 
The sensor requires liquid nitrogen to cool its infrared spectrometer detector.

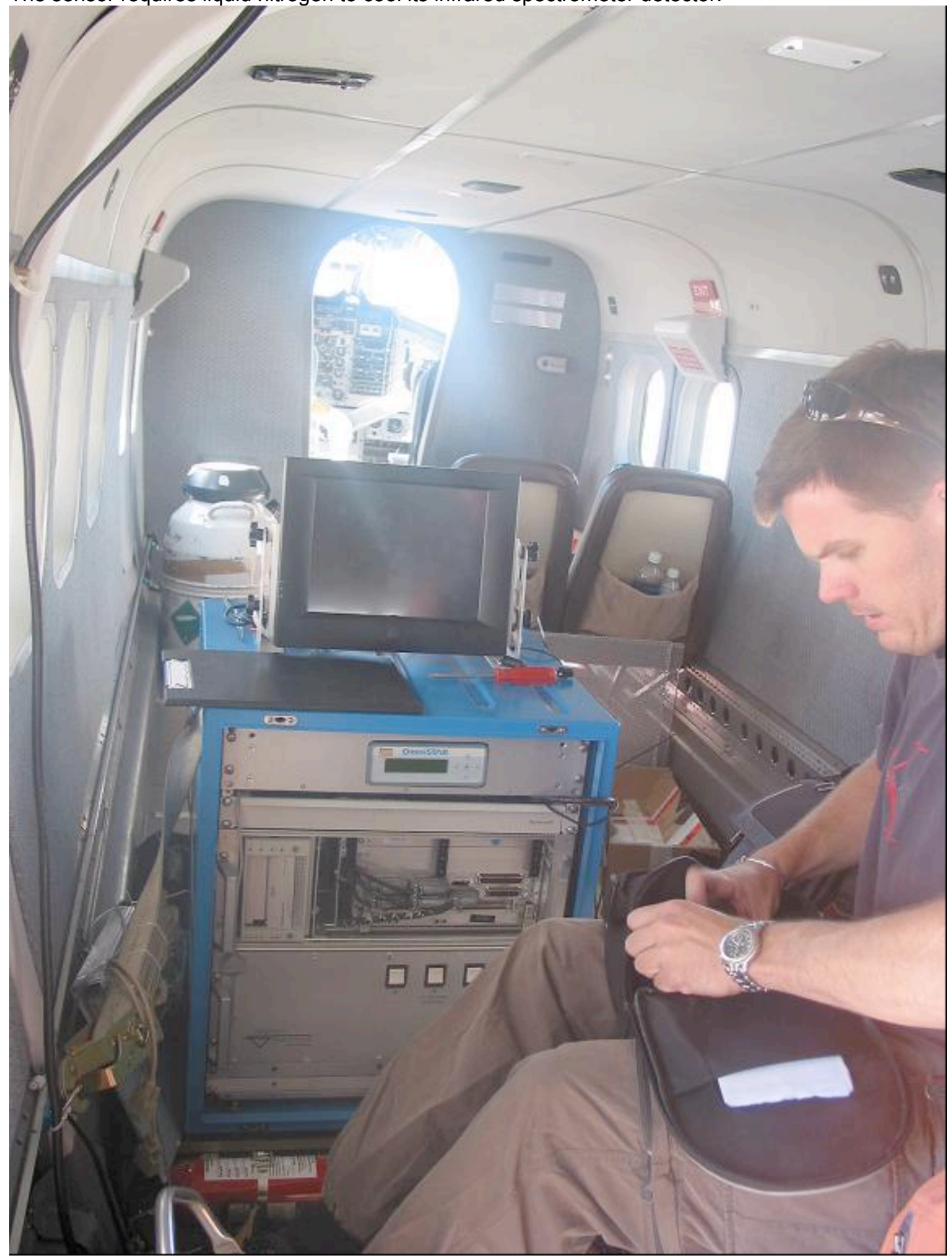

Figure 9. Ashley Hill is the acquisition contractor's sensor operator and flight commander. $\mathrm{He}$ is shown with the onboard computer system that controls the sensor systems and records the image, and the exact geolocation of each pixel in the image as it is acquired. The aircraft is the 
B300 Twin Otter.

\section{Results and Discussion}

We have done many analysis of the August 2002 Rangely hyperspectral imagery using ENVI. We have combined these with the photos, topographic maps, and digital elevation models we have of the Rangely Oil field, town and surrounding areas. All of the products are georectifiablle using the GLT files provided by HyVista as part of the imagery, as explained in the experimental section of this report. The accuracy of the precision of the georectification is about two pixels or 6 meters. The accuracy is also about 6 meters on flat ground. Our laptop computers are very fast and have large hard drives internally, so we were able to make a second field trip to Rangely in August 2003 with all our analysis results with us. We actually had the laptops running ENVI with all the results, with us in the SUV every day as we worked in the field. Before making the second trip in August we were actually confused by the complex and highly detailed mapping that was emerging from the analysis work we had done at LLNL and UC Santa Cruz. By having the analysis products available georectified opened and running in ENVI in our vehicle we were able to drive to precise locations within the areas that emerged from the mapping analysis. We then were able to observe the areas, and the adjacent regions. Soon it became clear what had happened. The analysis algorithms, particularly the ENVI SAM analysis had picked out "habitats" or local ecologies. We walked the perimeter of the habitats with a hand held DGPS recording a "waypoint" every few meters. We then downloaded the waypoint list from the handheld DGPS and compared the pattern to the perimeter of the habitat area that was mapped by the ENVI analyses. The two agreed virtually exactly, in all the details, within about 3 meters. This was a remarkable result and gives confidence that we are now interpreting the mapping results appropriately. 
The Field Site

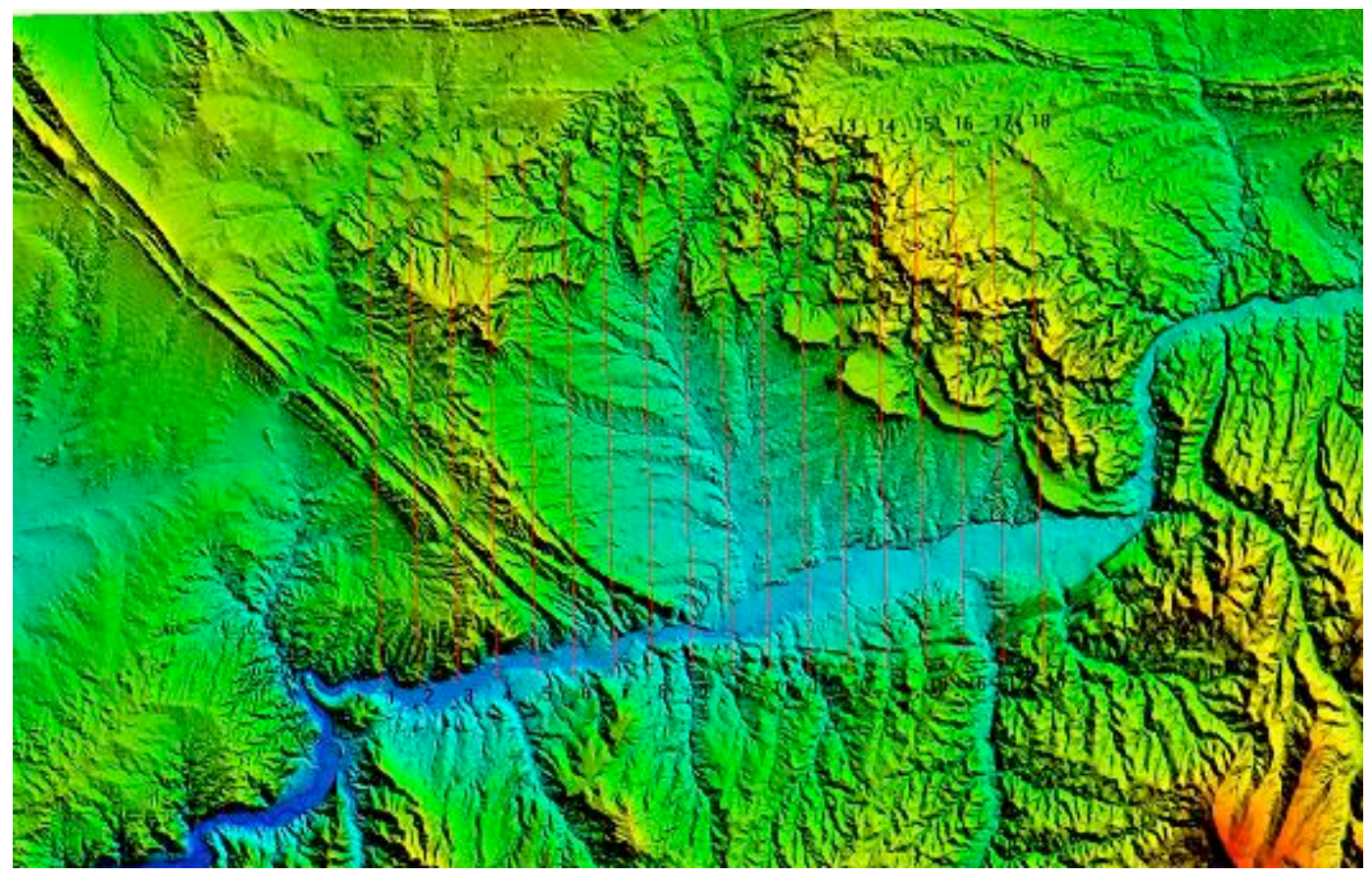

Figure 10 This is a digital elevation model of the Rangely Oil Field basin and surrounding formations with flightlines.

The White river basin is shown running from the center right to the lower left corner. The Rangel Oil field basin is in the center of the figure. The 18 flightlines that were flown to acquire the 18 strip images are shown in red. They are exactly due north and south by design. They are labeled 1 through 18. The town of Rangely $\mathrm{CO}$ is located in the White River Basin close to line 14 . The folded formations whose motion created the oil field are easily seen running from southeast to northwest on either side of the basin and east west across the top. Mellen Hill and the Mellen Hill fault can be easily seen at the north west end of the oil field basin. 


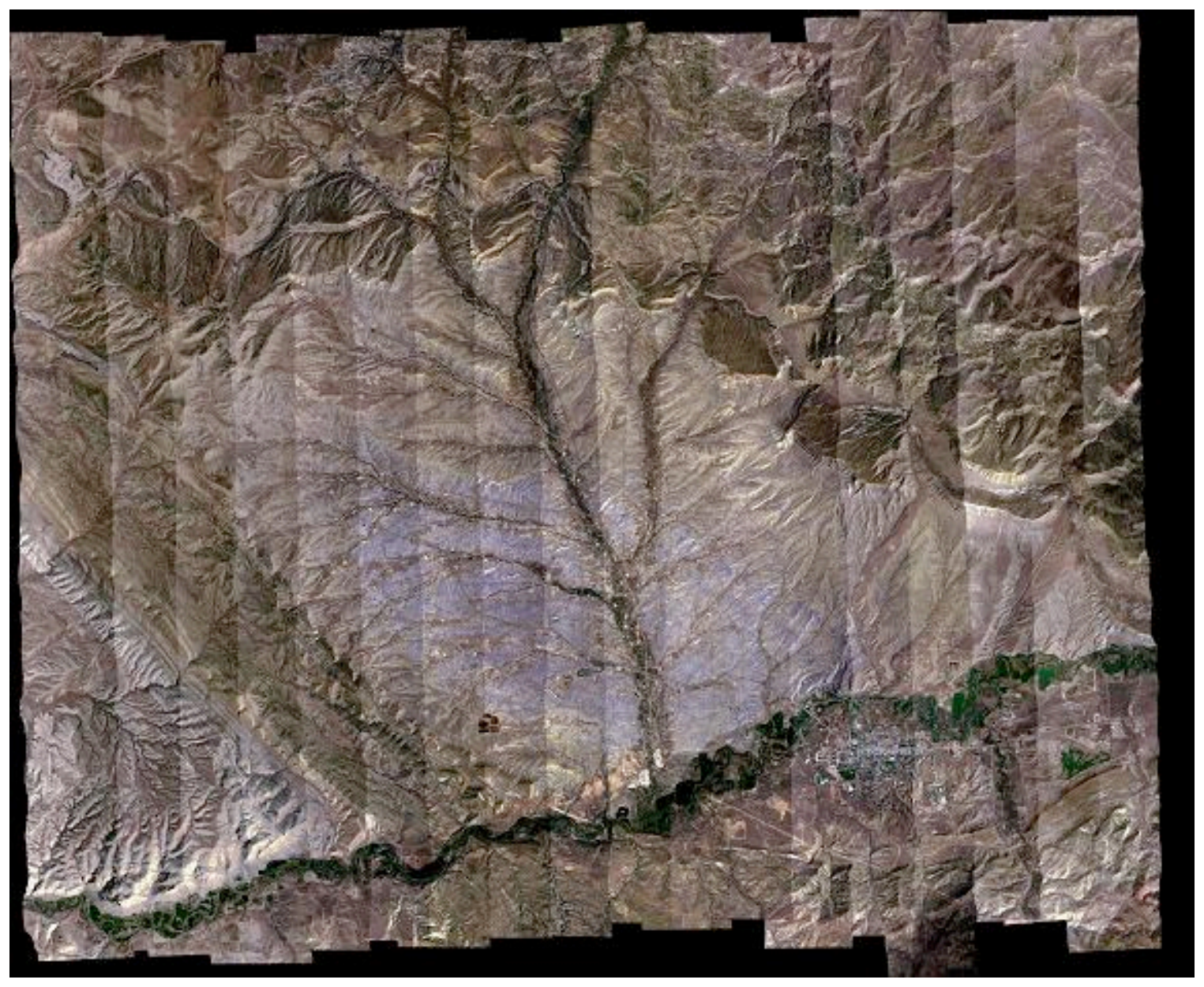

Figure 11 All the flight lines used to make a "true color" RGB image of the whole Rangely Oil Field basin, the surrounding formations and the town of Rangely.

The individual flightlines are all georectified and therefore they can be mosiaced together to produce an image of the whole region. All of the imagery shown in this report is georectified and true north is straight up on the page.

We have analyzed all the flightlines for the level of "plantness" with an "NDVI" ratio formula that uses individual bands in the hyperspectral image. The result is a computed ratio formula image that is normally called the "NDVI" or Vegetation Index image. The NDVI numerical value is high for lush green plant life and low for soils or manmade objects.

The NDVI images of each flightline were mosiaced together to produce the composite NDVI image of the whole region. The resulting NDVI image is shown in figure 12 as a grayscale image. It can be presented as a pseudocolor image just as easily, but the grayscale image shows the results in a more understandable way. The brighter, or whiter, that a pixel appears, the more "healthy plant like" the contents of the pixel are. This means that the brighter the pixel in the image is, the bigger percentage of the pixel area is healthy vegetation. It also means that the brighter the pixel the healthier the plants in the pixel are. So the brightness of the pixel is a combination of the percentage of plant area coverage and the distribution of levels of health of the plants within in the pixel. Understanding exactly what the NDVI image is telling you is critical in this arid high desert environment, with its sparse vegetation. In general most plants are somewhat smaller than the 3 meter pixel size in the image. In between plants you can see low 
grasses that may be seasonally dry or you may see bare soil. You can have a very healthy plant smaller than 3 meters surrounded by dirt that will have some intermediate NDVI value. You would make a mistake if you said that because of an intermediate NDVI value there are no healthy plants in that pixel. Users interpreting geobotanical features from an NDVI remote sensing analysis unfortunately often make this kind of mistake. An additional mistake can easily be made using the NDVI for mapping plant health in high desert regions even when there is 100 percent of a pixel covered by vegetation. Some plants in these regions can look desiccated and brown on the outside while they are perfectly healthy on the inside. They are just waiting for water, or they are in their seasonal cycles. With all those cautions we still can make important use of this NDVI mapping of the Rangely region for $\mathrm{CO} 2$ leak detection and baselining.

In the first place, this NDVI map shows the exact location of almost every live plant in the entire region on a particular day. To zero th order, we can infer that there is less percentage plant coverage in the darker pixels. Darker pixels may also, however, have reasonable percentage of plant coverage, but the plants may appear highly desiccated or woody on the outside. Or both may be true. This can be resolved, for a particular location, by other additional hyperspectral image analysis or by simply driving to the exact location using a DGPS and observing what the plant coverage and health are. For very bright pixels we can infer a combination of good plant coverage and apparent health.

The NDVI analysis then does provide an important map for locating exact places for further study. In addition, it does show the very complex patterns of plant coverage/health. It provides a very good baseline snapshot of the geobotanical conditions in the field. If a $\mathrm{CO} 2$ leak of significant magnitude did develop, it is likely to darken the NDVI pixels in the area where the soil CO2 concentration has risen significantly, either because of decreasing plant percentage coverage or decreasing plant health or both. Judging from the tree kill areas at Mammoth Mountain, both would occur.

By inspecting the NDVI composite image in figure 12, we see that the oil field basin appears generally dark. The basin does have relatively low percentage plant coverage in most open flat areas, and the plants also appear woody or desiccated. Most of the plants in the basin are in fact perfectly healthy; they are just well adapted to their environment. In the arroyos, streambeds and drainage patterns there is a significantly higher percentage of vegetation coverage, and many different types of species that appear less woody and have more green showing. These areas in the basin are brighter in the NDVI image. The surrounding areas that are higher in altitude have much higher vegetation coverage and species that are very much greener. These areas also much brighter in the NDVI. The white river basin the runs across the bottom of the image has very high plant coverage and it is lush green. These areas are the brightest of all in the NDVI. The town of Rangely that is just south of the White River has many lush green areas such as the golf course which is the very bright object in the lower right corner that looks somewhat like a poorly tied bowtie. 


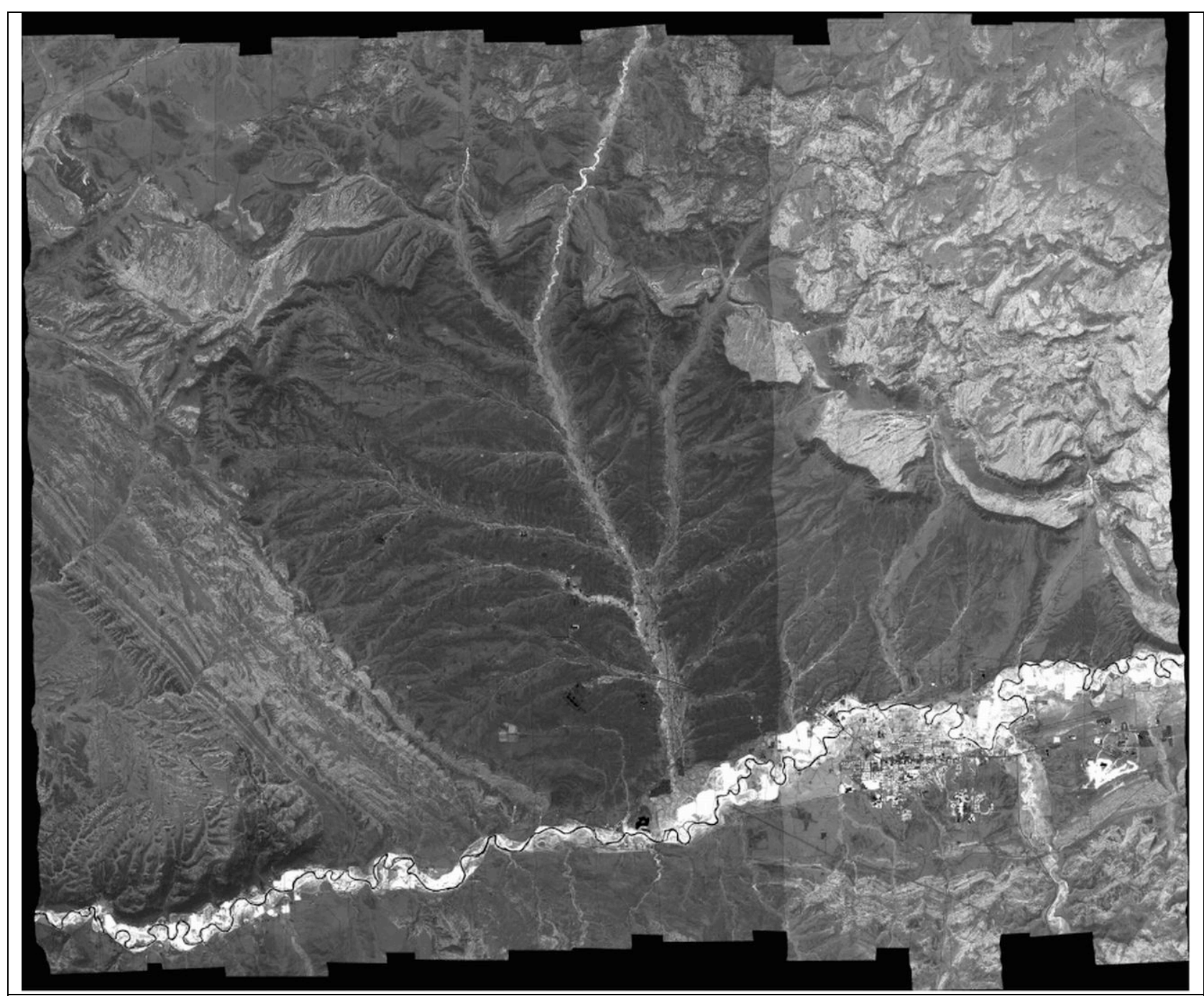

Figure 12 All the flight lines images converted to NDVI images and mosiaced. This is a gray scale image. The whiteness or brightness of each image pixel means both that there is a higher percentage of plant coverage in the pixel area and or that the plants are exposing more chlorophyll in their leaves and stems.

The NDVI mosaic shown in figure VV clearly shows the difference in the plant health before and after the first rainstorm of the season. The flightlines on the left, numbers 1 thru 12 were acquired on Tuesday. Then it rained for the first time in the summer on Wednesday and Thursday. Then the flight lines on the right, numbers 12 through 18, were acquired on Friday, which was a beautifully clear day. The flightline number 12 was reacquired to provide a direct comparison of before and after rain on the plants in the same flightline. The two flightlines $12 \mathrm{~A}$ and $12 \mathrm{~B}$ are shown in figure 13 below. 


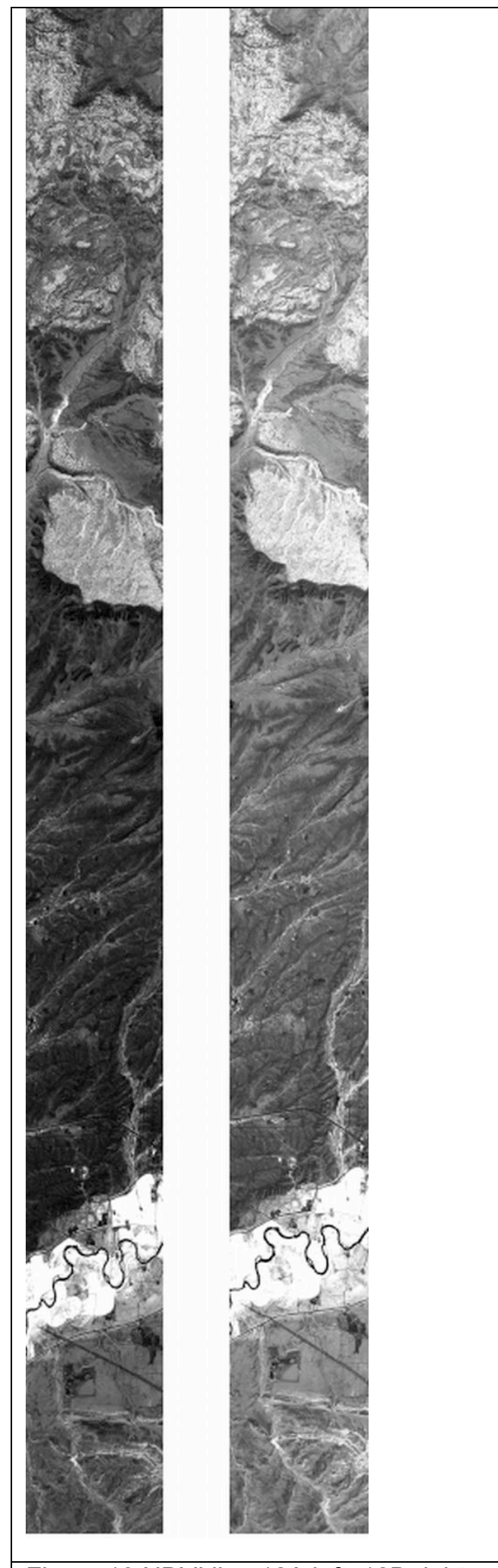

Figure 13 NDVI line 12A left, 12B right
The NDVI produced from flightline 12A acquired before the rain storms is shown on the left in figure FF. The NDVI produced from flightline $12 \mathrm{~B}$ is shown on the right. In studying this carefully we find that most pixels are brighter, or whiter, in 12B. This what we expect if the rain did trigger the high desert plants into increased photosynthetic activity. There are some pixels in 12B that remain as dark as the same pixel in $12 \mathrm{~A}$. These are probably pixels with only soils or manmade objects in them. When we were on our second field trip at Rangely we noted that most areas had vegetation cover. The rain probably activated many of these high desert species. This hypothesis is in agreement with the wide spread elevation of the NDVI values between $12 \mathrm{~A}$ and 12B throughout most of the area imaged.

The arroyos and washes in the basin and the junipers on top of the surrounding higher elevations seemed to have brightened the most, as you would expect. Also it appears the complex pattern of vegetation distribution has not changed, only the relative observable photosynthetic activity. This is a very important observation. The plants have not had time in two days of rain to change their habitat distributions. This comparative NDVI mapping shows that clearly. This is very encouraging for us. We feel this shows that we have a reasonably correct view of the overall response of plants and habitats to natural environmental variations and understand the time scales involved. That increases our chances of being able to detect and discriminate $\mathrm{CO} 2$ soil concentration induced anomalous habitat distribution changes at an early stage. It also shows the power of having repeat imaging of the area to be monitored. Imaging seasonal and weather-induced variations may be very powerful for the early detection of elevated soil $\mathrm{CO} 2$ concentration effects on the plants and habitats. 


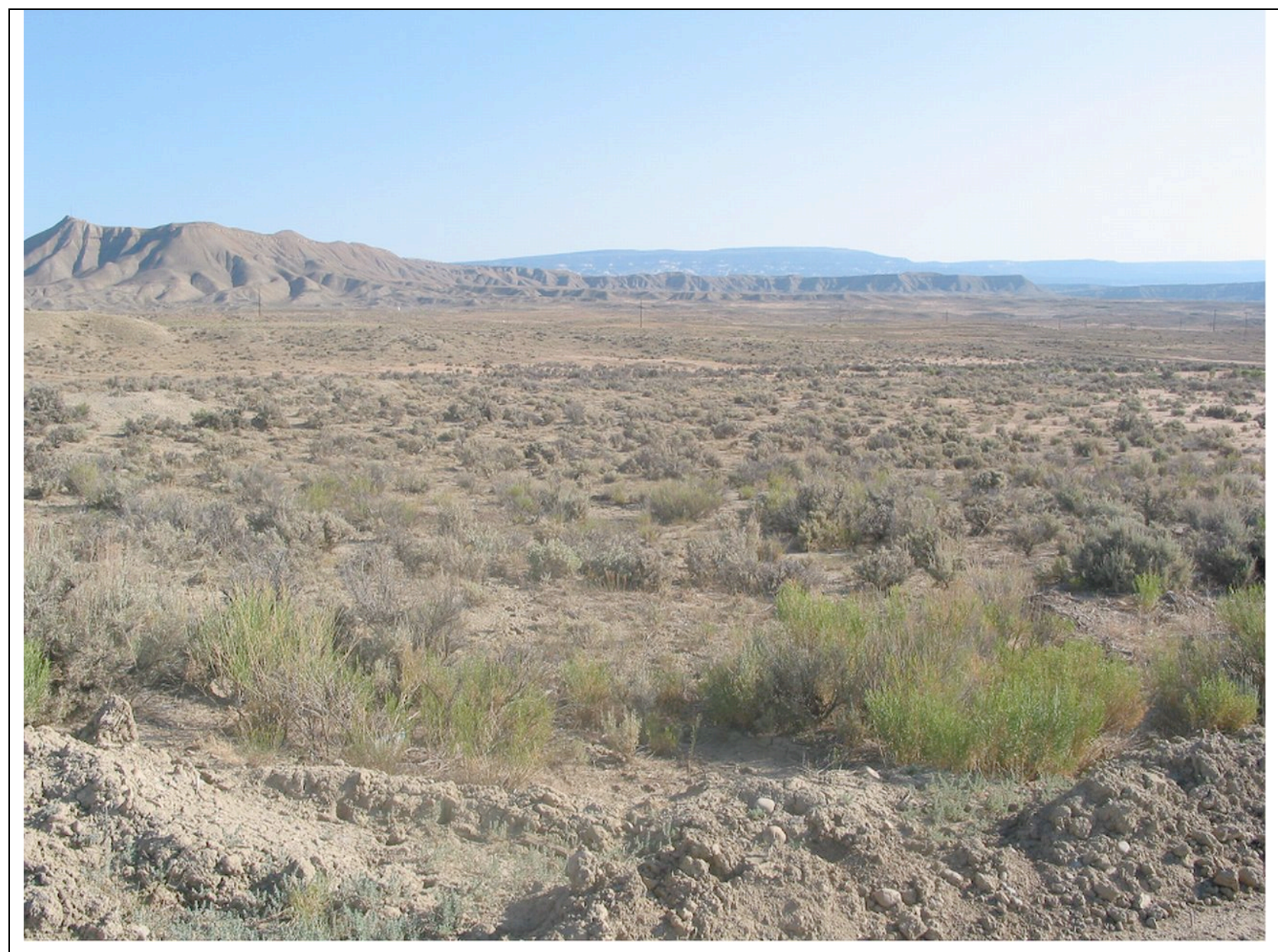

Figure 14 View of the Rangely oil field south of Mellen Hill.

This area was imaged at about the top three quarters mark in flightline 3. Our examples of detailed mapping in the oil field using the hyperspectral image analysis that are presented in the following sections, includes the area in the photograph. Please take time to locate the well pads, roads, vegetation, vegetation patterns or habitats and various soils in the photo. 


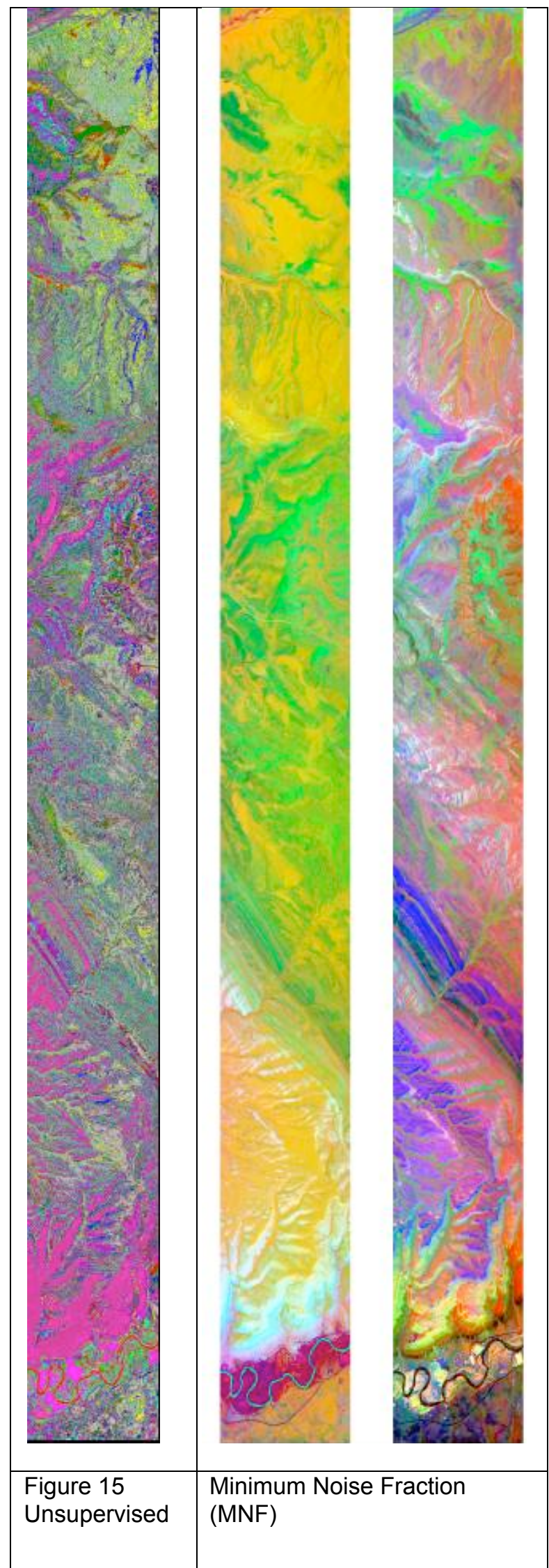

On the left in the adjacent figure 15 is an unsupervised classification of flightline 3 done using ENVI. In this analysis, an algorithm separates the pixels in the image into some number of groups, in this case 35 groups. Individual pixels are grouped so that the complete spectral signatures and brightness are most similar for the pixels in each group. I like to think of this process as what you would do if I asked you to sort a pile of multicolored "Indian corn" kernels into smaller piles where the kernels in the new piles were most like each other in size, colors, and patterns. As you went thru the process you would create more and more separate piles. Then if I asked you to limit the number of piles you would be forced to recombine piles. In recombining two piles you might decide to resort the piles along with several other piles to reduce the overall number of piles. This could iterate for a long time so at some point we would call halt to the process unless you had decided that the piles were not changing much between iterations. This is exactly what the unsupervised classification algorithm does using the brightness and spectral shapes in each pixel. This process is "blind" in that there is absolutely no information about what is causing the brightness or spectral shape in the pixels involved. This is always a wise step to take at the beginning of analyzing imagery of a new area, because it alerts you to the complexities of the region. This result is georectified as are all the analysis products after they are created. Therefore it can be used as very effective tool to sort out different types of soils, plants, etc, during a subsequent field trip to the site. Unfortunately this method of classification is very sensitive to the overall brightness of the pixel. We used this type of analysis initially to tell us the quality of image data that had been acquired. As you can see in the figure $\mathrm{CC}$ shown on the left the large number of categories and the complexity of the patterns indicates that the imagery is extremely information rich.

The two images on the right are the analysis of flightline 3 using the ENVI Minimum Noise Fraction (MNF) procedure. In this procedure the original 128 bands of spectral information in each pixel are transformed into a new smaller set of objects that are referred to as MNF "pseudo bands". They are not spectra any more, but they are "pseudo bands" that contain the most noise free information that 
was in the original hyperspectral image. MNF "pseudo bands" $1,2,3$ are presented as RGB in the center image. MNF pseudo bands 4,5,6 are presented on the far right. This step in the ENVI "hourglass" procedure shows that there is a very large and detailed amount of information contained in the hyperspectral image. We did not use the MNF results as our final step. 


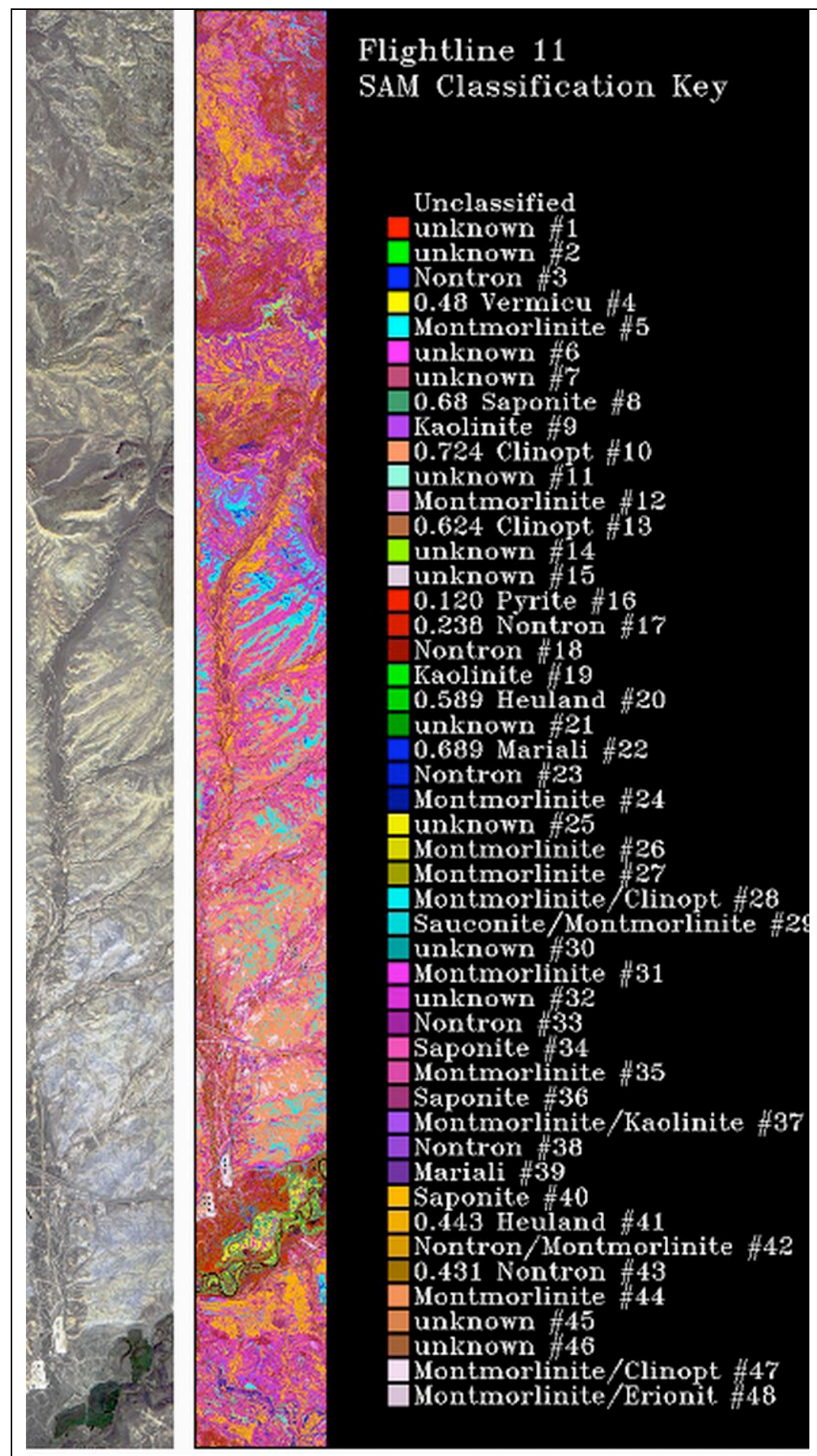

Figure 16 Detailed habitat mapping that results from an ENVI "hourglass" process. This process ended with a Spectral Angle Mapper (SAM) analysis of flightline11 that is shown in the center. On the left is a "true color" RGB image of flightline 11
We continued on to do a Spectral Angle Mapper analysis that is shown in this figure 16.

The ENIV "hourglass" ending with a Spectral Angle Mapper (SAM) Analysis is the method that we have found to be most able to detect and discriminate plant habitats or ecology types, soils, mineralizations, water conditions, and manmade objects. Figure 15 on the left is an example of the result of using this process on the flight line 11 hyperspectral imagery. 58 categories were found. They are shown in the analyzed flightline 11 image in the center. They are mapped using different colors that are shown in the legend on the far right. Many categories were tentatively identified using the USGS mineral spectral library, which we found to be a reasonable guide to what we actually found when we visited the locations of the categories during the second field trip taken in August 2003. The unknown categories were found to be mixed vegetation "habitats" when we went back into the field at Rangely with these analysis products. During the fieldwork we used georectified analysis maps such as this one in our laptops and DGPS in our SUV to accurately locate and identify these categories at many places in the oilfield, town and surrounding areas. 
There is "True" color image made from Flight line 11 Bands 15,9,2 as RGB on left. Note the difference between a color "picture" on the left and the SAM analysis for mixed vegetation "habitats", soils, and water on the right.

This process was repeated for all the flight lines. 


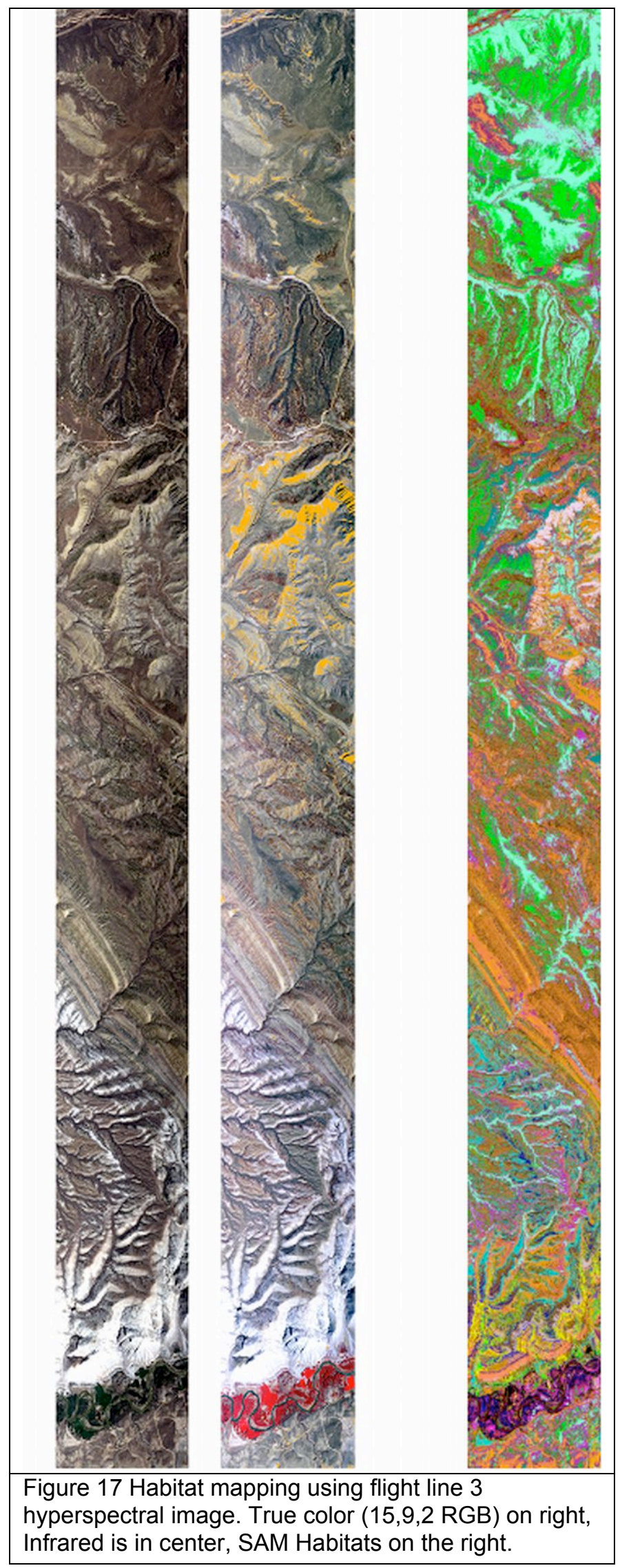

We have found a result that was unexpected, new to us, and potentially very important to the task of monitoring for $\mathrm{CO} 2$ that has leaked to within the plant root depths near the surface. The discovery is that one of our analysis techniques, the ENVI SAM analysis has picked out finely detailed mapping of local ecologies or "habitats". Some of which are found to extend across the entire Rangely oil field and into the surrounding areas. These ecologies appear to be made up of a narrow range of percentage admixtures of two or three very specific plant types and soil types.

We found this result serendipitously by returning to the field at Rangely with all our analysis products and the ENVI program running in our laptop computers. The products are all georectified and so we were able to drive to the exact locations that were being picked out by the analysis and visually inspect them. We were able to walk back and forth between adjacent areas that were being picked out by the analysis. After a while, it became apparent to Wendy Cover what had happened. The computer analysis was sorting out regions based on the relative mixture of plant types, plant sizes, plant spacings, intervening ground cover such as grass types and soils. With in these regions things like roads, paths, animal trails, manmade objects such as oil well pad areas, tanks, buildings are all also apparent and are picked out separately by the algorithm.

The area where we discovered that our analysis was picking out habitats is in the flight line 3 image. The SAM analysis of flight line 3 is shown on the right hand side of figure YY. The SAM analysis categories shown in light blue and in green were found to be two distinct mixed vegetation "habitats" surrounded by a third distinct habitat when we went back into the field at Rangely with these analysis products. The habitats consist of healthy sagebrush, mixed with golden dry cheek grass, and a percentage of dry 
soils. We found these two habitats were all over the Rangely region once we learned to recognize them from the SAM analysis. This result was unexpected and is a powerful means of mapping subtle meso-ecologies or "Habitats" with mixed vegetation and soils

The other images in shown figure 16 are a "true color" of flight line 3 made with Bands 15, 2, 9 as RGB on the left. In the center is a different 3-band image used to produce the equivalent of an infrared photograph, called a "color infrared". Then an analysis that maps the mineral Montmorillonite and Kaolinite in soil mixtures, shown in yellow-orange, has been laid on top. The lush green vegetation that is found primarily near the White River appears in red near the bottom of the image. Healthy vegetation reflects very strongly in the near infrared and so it appears very bright. The "color infrared" image is made from the hyperspectral image using the bands 27, 16, and 7 as red, green, and blue respectively.

The area includes the Rangely Oil Field. In our previous experience, these soil mineralization maps are extremely accurate in arid regions, which this region certainly is. 


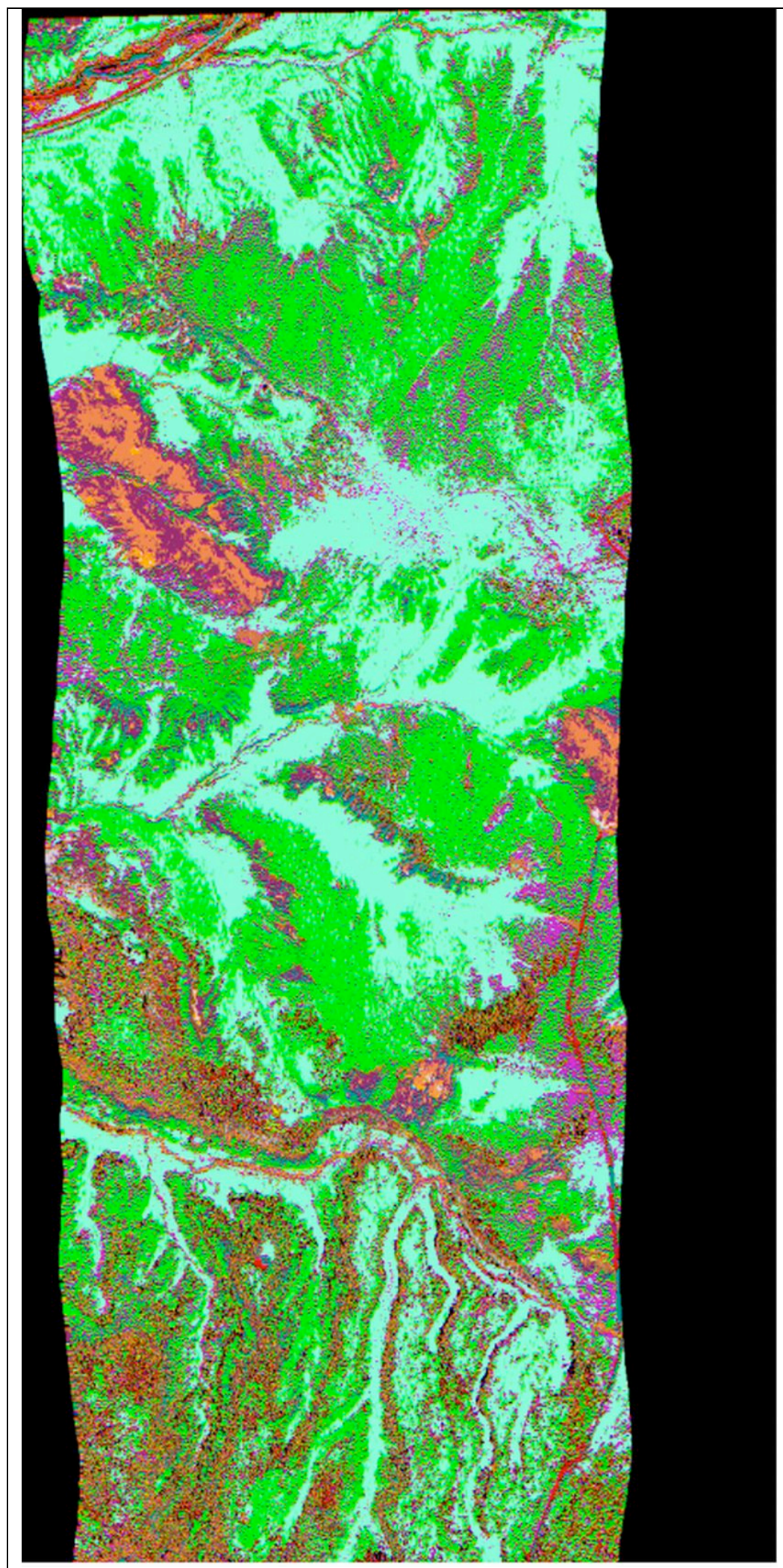

Figure 18 Close up of line 3 SAM analysis showing the newly discovered habitats.
Figure 18 is an enlarged view of the SAM analysis for the top of flight line 3 showing two of the habitats discovered by using the imagery analysis to guide us in the field. Light blue was found to be healthy sagebrush, mixed with golden dry cheek grass, and almost zero percentage of dry soils. Dark green was found to be smaller sagebrush plants mixed with cheek grass but with dry soil showing over about $50 \%$ of the area between the sagebrush plants. The delineation was remarkable. We walked the edges of some of these areas with DGPS and found the mapping to accurate to 1 or 2 pixels! We feel any $\mathrm{CO} 2$ leakage would begin to affect the shape of these habitats and hence be easily seen in subsequent reimaging as a change. Of course that would only target the changed area and map it so that a team could go to that spot and check for excessive $\mathrm{CO} 2$. This would also target a place to put small "nano-bot" smart $\mathrm{CO} 2$ sensors that can be integrated remotely and provide $\mathrm{CO} 2$ concentration by telemetry to a central facility.

Photos of these two habitats are shown in Figure 21 and Figure 22. The top two photos in Figure 21 are of the habitat mapped by the light blue SAM category in figure 18. The bottom photo is of the habitat mapped by the green category in the SAM analysis. The location of this habitat area is shown in Figure 19 and Figure 20 by the DGPS waypoints shown as red dots. The 
DGPS was left on all day each day in the SUV and recorded the "trip". Figure 22 show Wendy Cover taking reflectance spectra of a plant using the ASD field spectrometer at the southern boundary between these two habitats. 


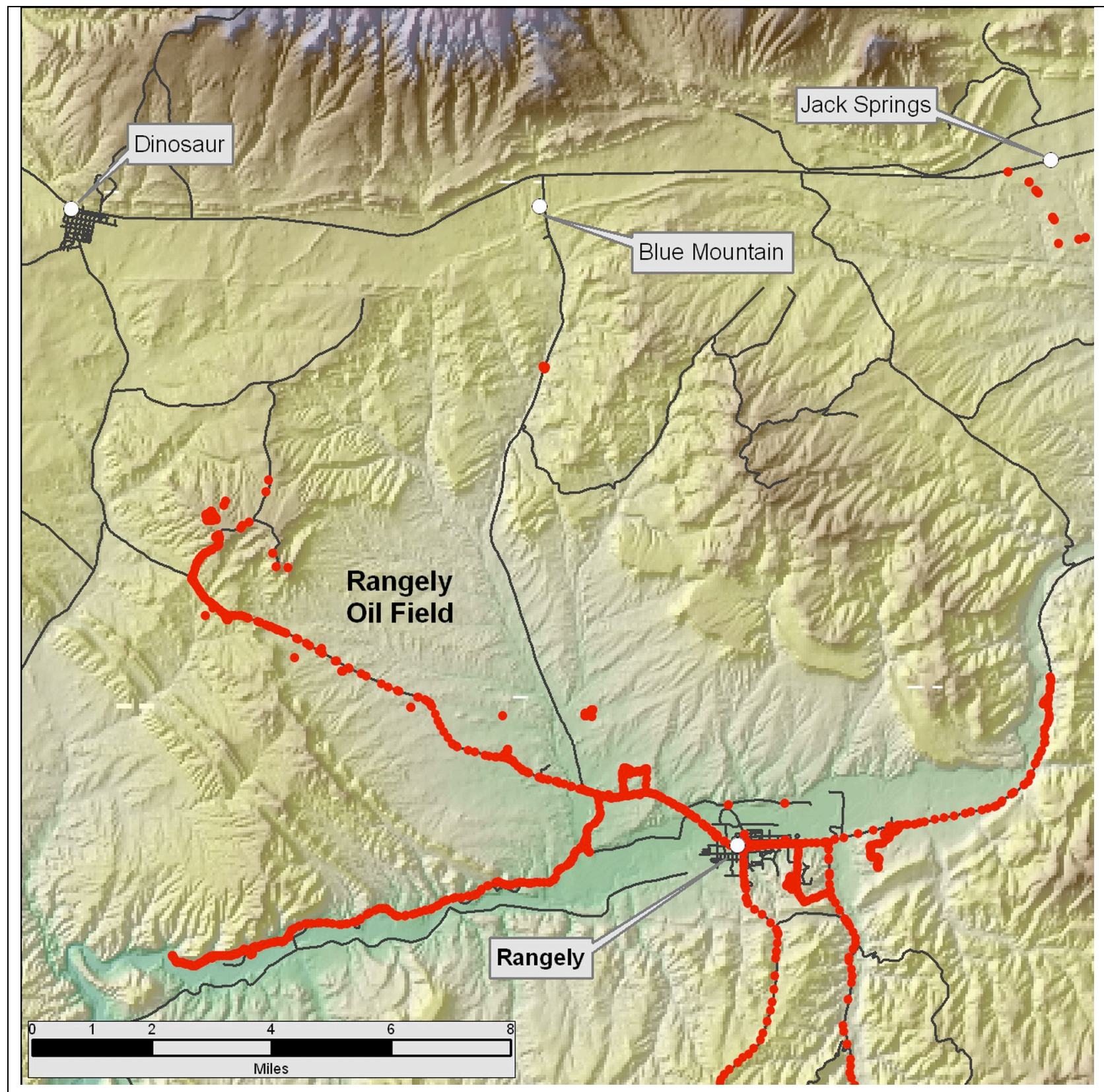

Figure 19 Continous recording of our handheld DGPS "track" during one day of the July 2003 field trip showing the sites visited that lead to the creation of the "habitat" mapping concept. 


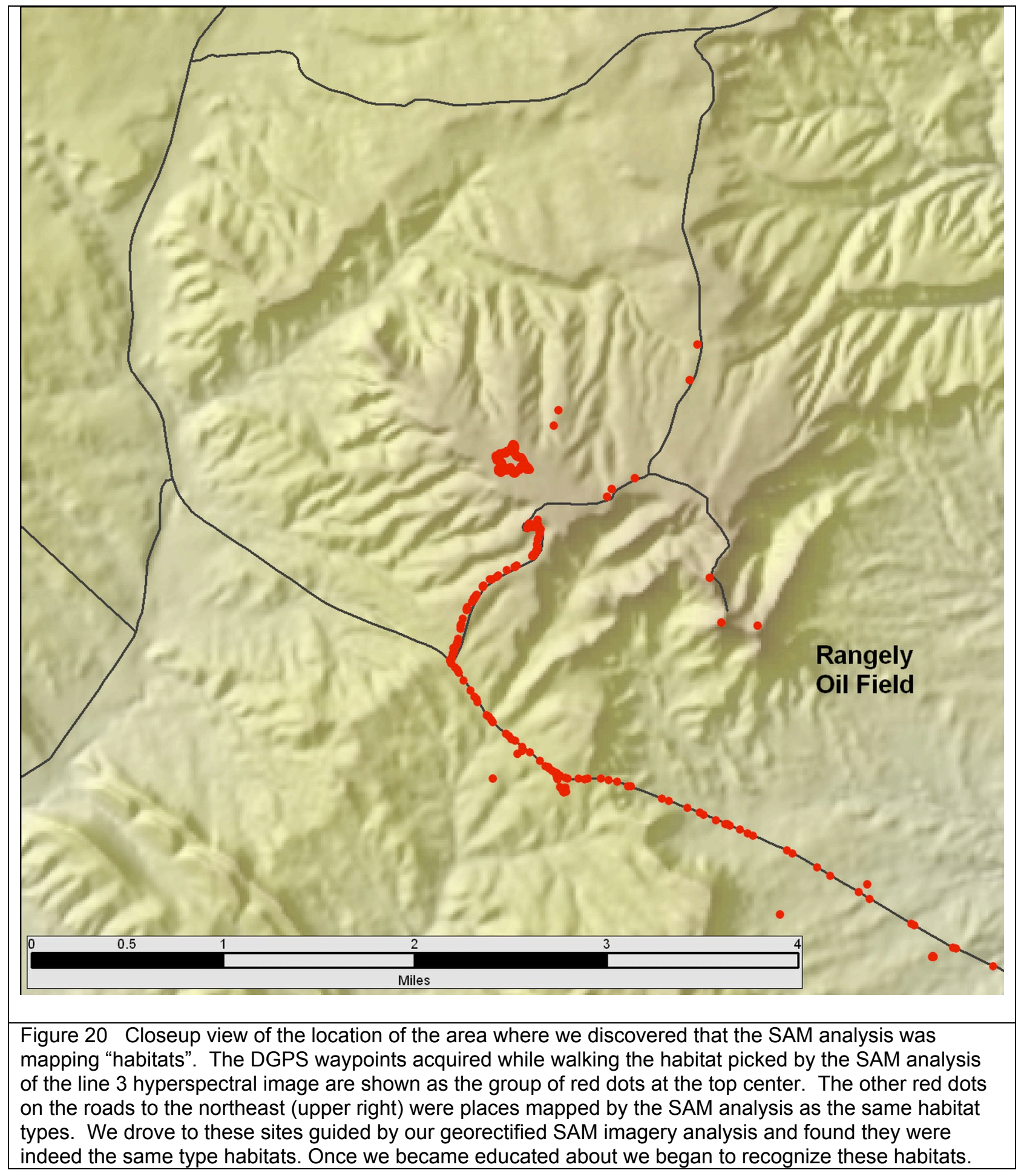



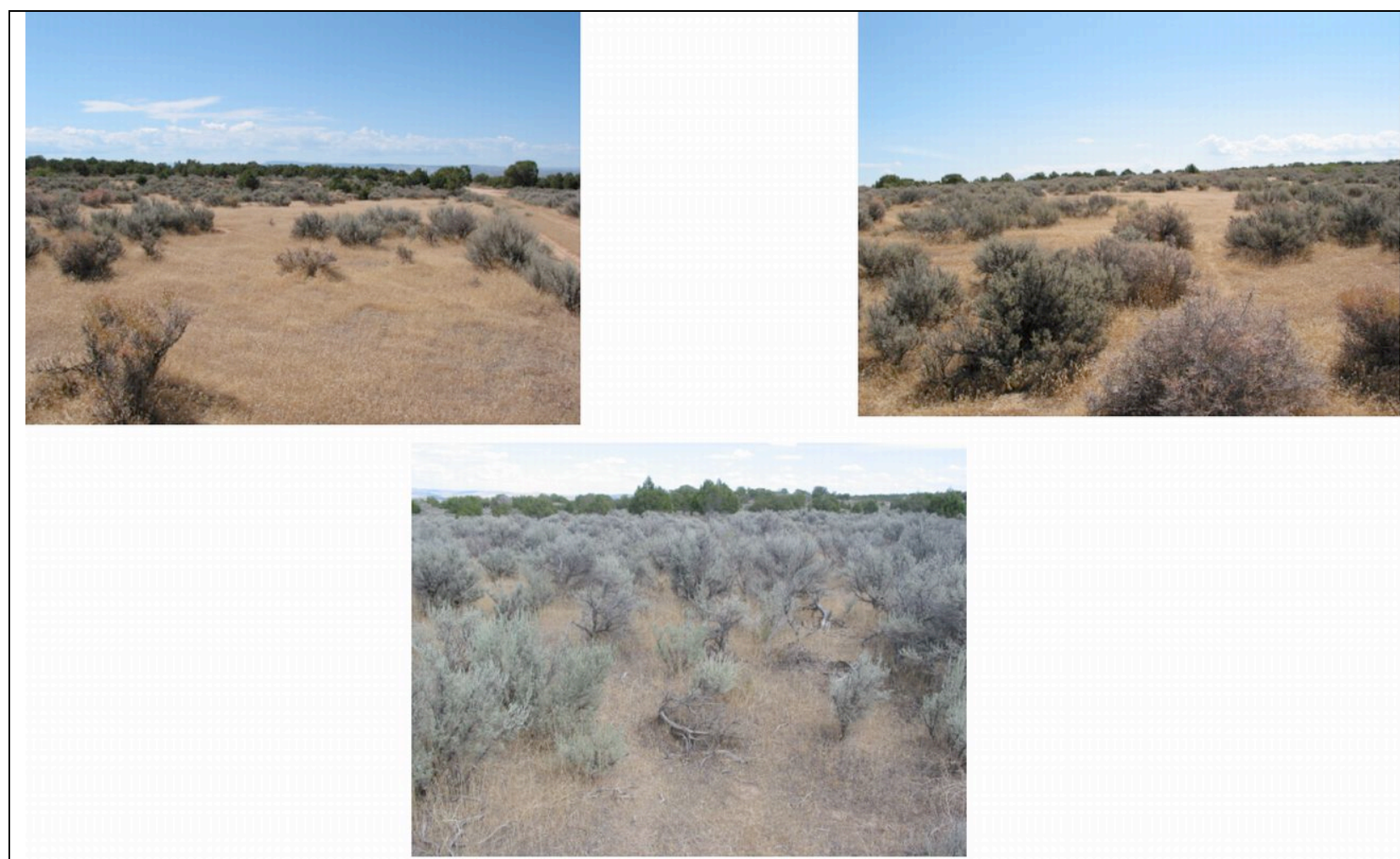

Figure 21 The two adjacent habitats discovered by using the line 3 SAM analysis categories.

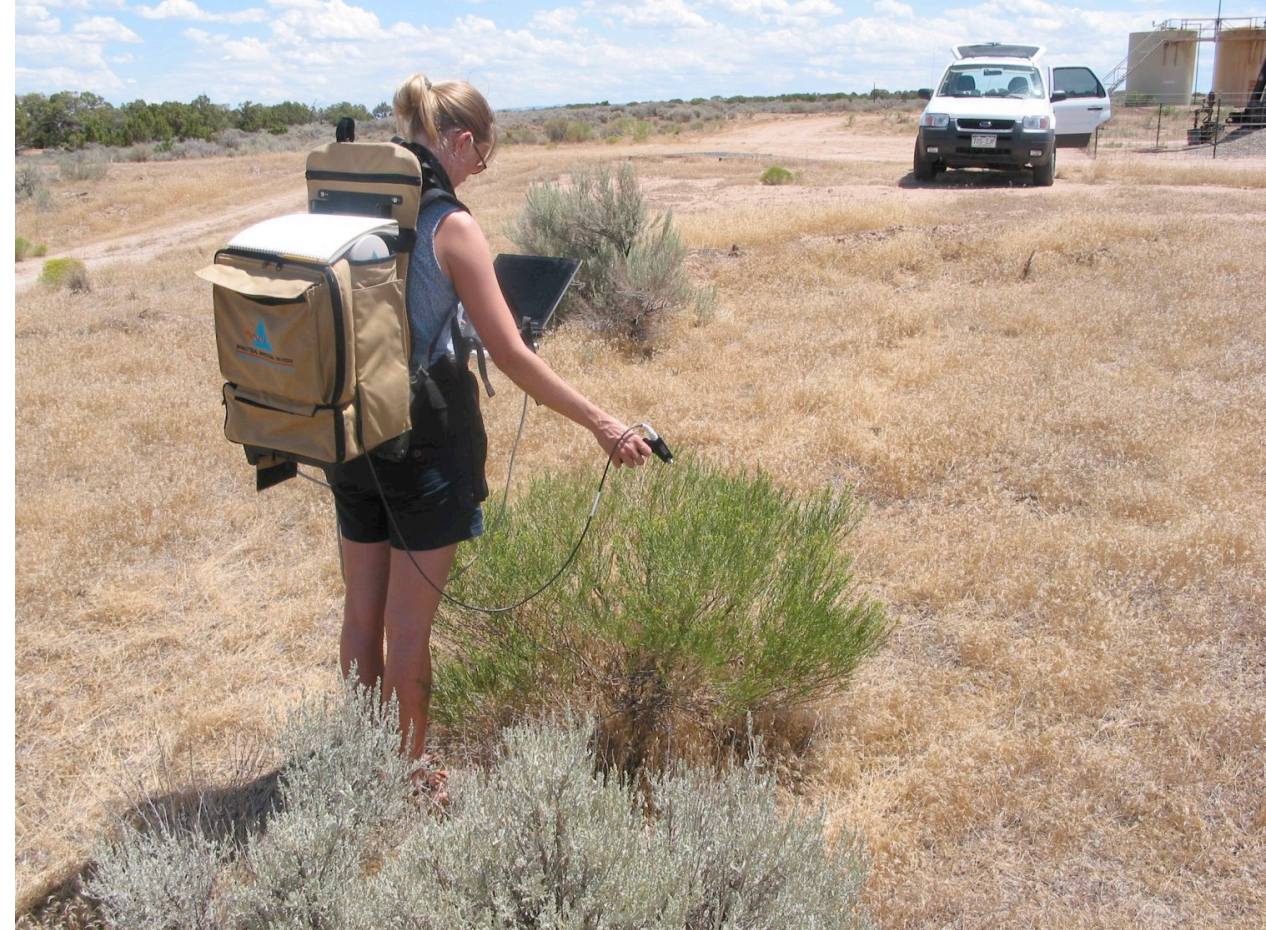

Figure 22 Wendy Cover measuring reflectance spectra of a plant at the border between two habitats. Notice the well pad and our SUV "mobile office" which had the laptop running with her SAM results. 


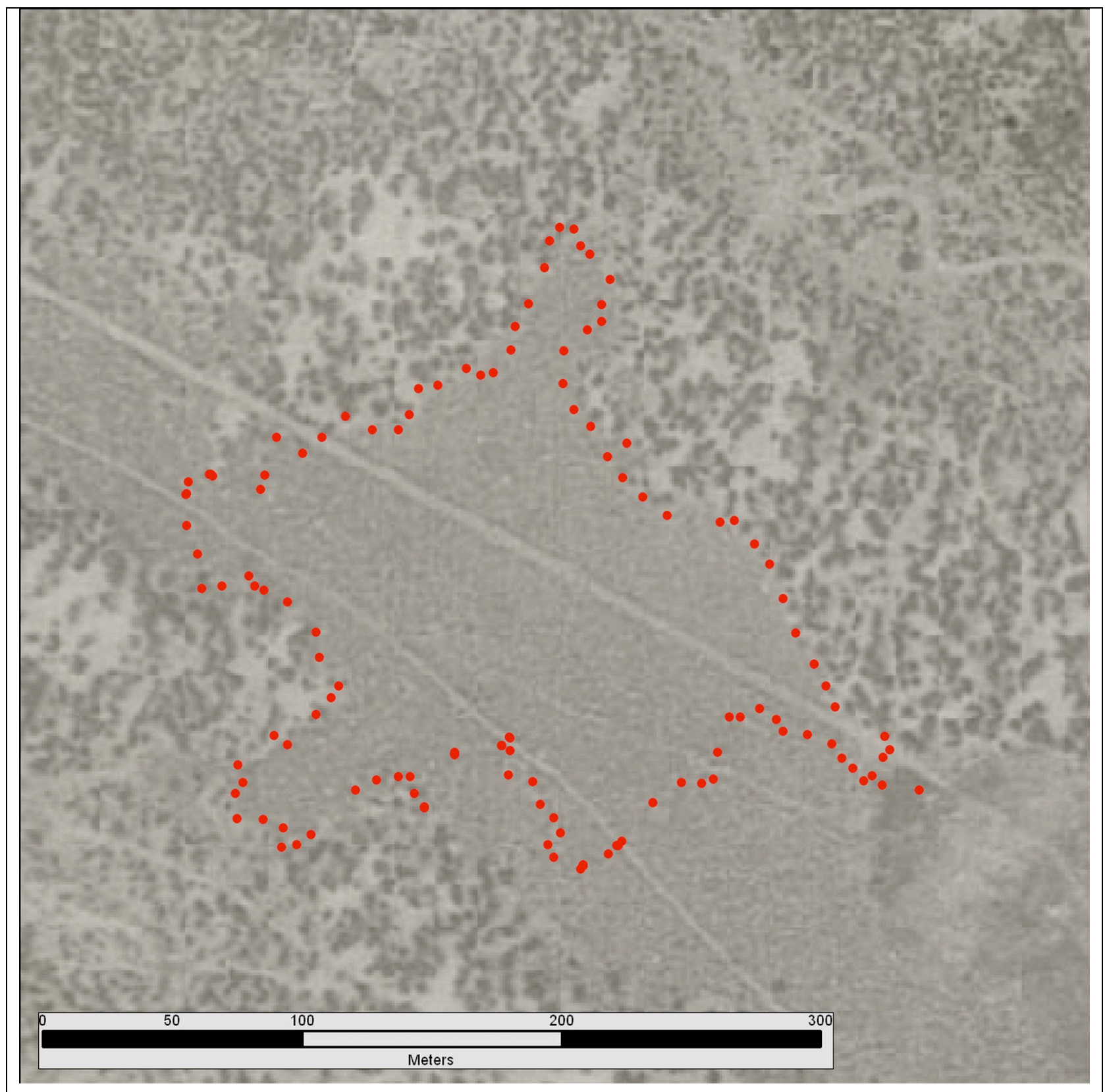

Figure 23 The red dots are DGPS waypoints collected by walking the perimeter of the habitat shown in the top half of figure 20. The DGPS points are shown overlaid on the 1990 airphoto.

The match between the DGPS waypoints (red dots ) collected by walking the perimeter of the habitat shown in the top half of figure 20 and the 1990 airphoto is remarkably accurate just as it is with the SAM analysis of the hyperspectral image. The exception is the area shown in the upper left. Apparently the habitat has been stable over the 23 years, except that junipers have intruded into the area along the two roads to the northwest just outside the boundary observed in July 2003. The area outside the red dot DGPS boundary to the lower left is the other habitat shown in the lower half of figure 20. The circular pattern in the lower left is a well pad. Our SUV "mobile office" was parked at the eastern most red dot at the edge of the well pad.The red dot just to the west was where the photo of Wendy Cover making the handheld spectrometer measurements was taken. It is the actual boundary between the two habitats. 


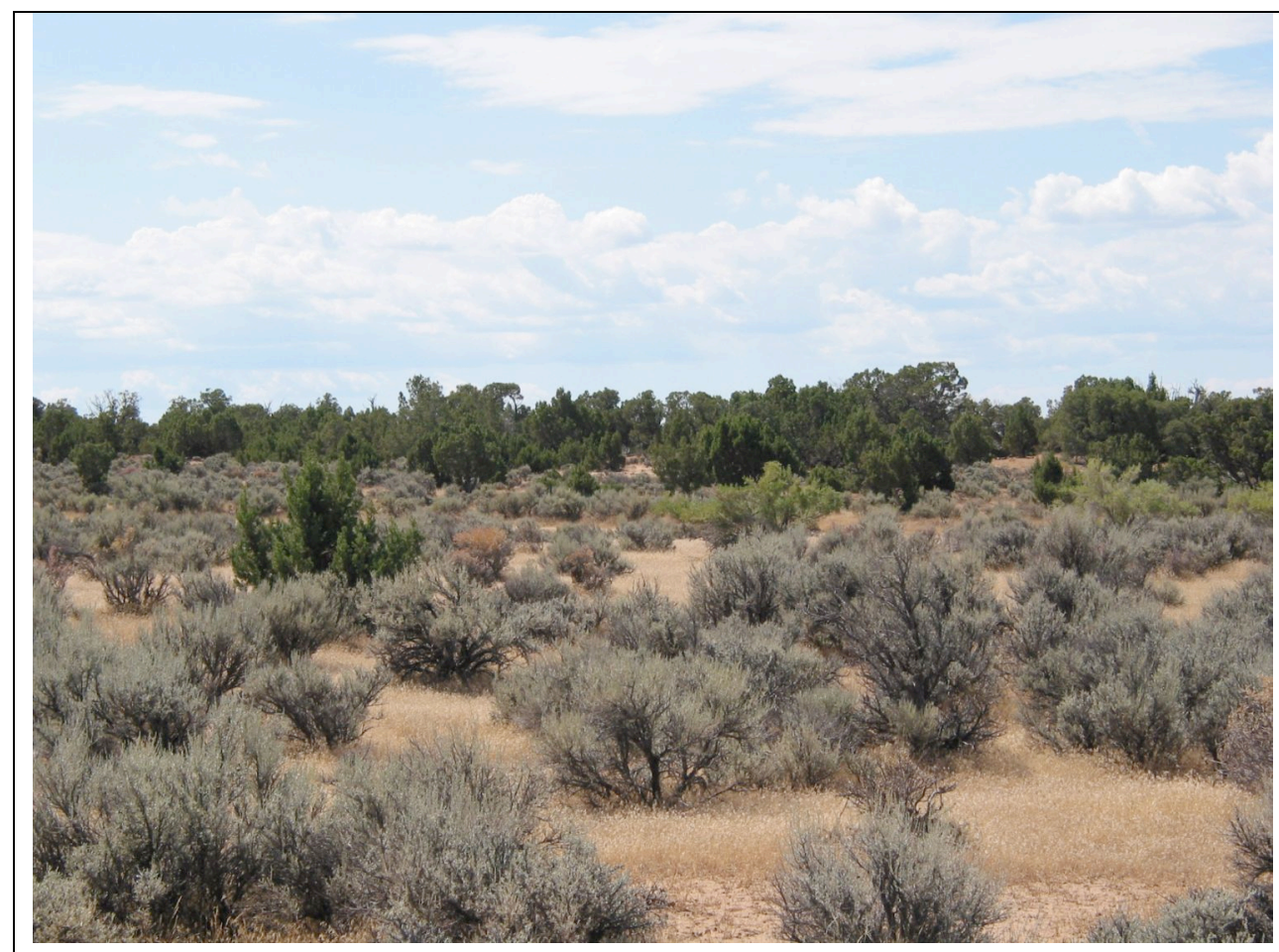

Figure 24 Northern boundary of habitat and the next habitat of Junipers. The edge is accurately mapped by SAM analyisis and the DGPS waypoints (red dots)

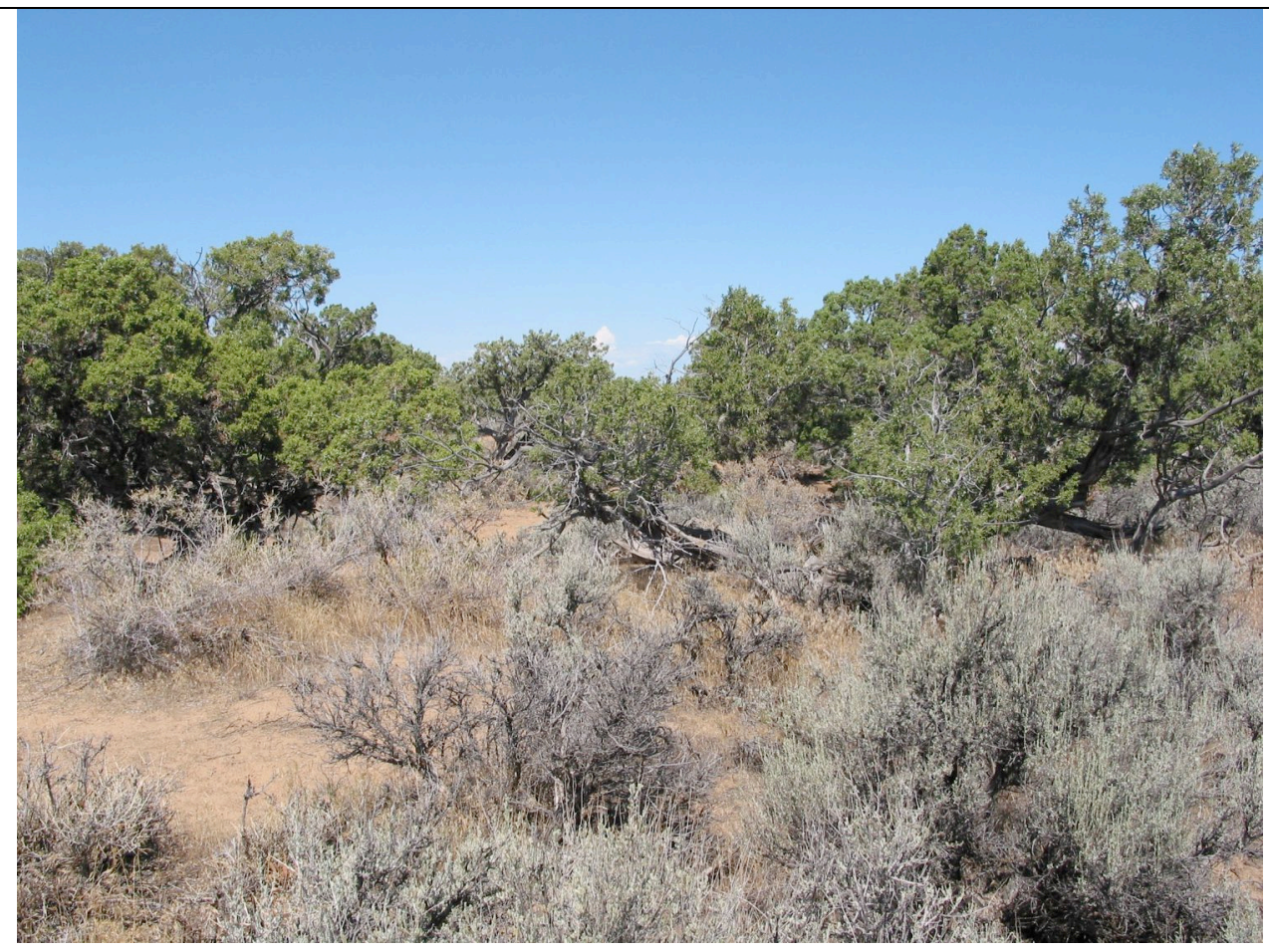

Figure 25 Closeup of the northern boundary between habitats. This is the top if the "finger" in the top of the DGPS waypoints (red dots) shown in figure 22. 
By carefully selecting ENVI SAM "endmembers", we were able to map four of the most obvious "habitats" or ecologies, , in all the flight lines imaged at Rangely. The results are remarkable in that these ecologies are discernable and mapable even though the eastern $1 / 3$ of the flight lines that were acquired on Friday after the heavy rains on Wednesday and Thursday. This leads us to believe that we are indeed mapping ecologies in this SAM analysis. This is very important because we can then turn these complicated and detailed maps into "masks" to be laid over the full imagery set. We can now begin to explore any possible plant health signatures with in the very well defined ecologies. We have not done that as part of this work but we would like to explore this avenue of research in a follow on project if that becomes possible. The figure19 below shows the four ecologies in four different colors. The black pixels are all other categories. The mapping is accurate to the individual pixel ( 3 meter in size) level through out all 18 flightlines of the entire Rangely region, including the imaging on the western side before and imaging on the eastern side after the first seasonal rainstorm.

We feel this demonstrated ability to do regional scale meso-ecology mapping form the hyperspectral imagery is a new discovery for us. It does establish the basis for further progress in the refinement of these methods. This demonstrates the powerful regionality of these imagery analysis techniques. This result is supported by the NDVI regional map (Figure 11) that shows that externally observed individual plant health does improve remarkably after the rains, but that the spatial plant distributions remained very constant. So we feel that our observation results are fitting into the orderly understanding of these detailed habitats and their behaviors in response to the natural climatic cycles. Then hopefully by observing deviations from these normal patterns we may be able to detect the effects of an abnormal infusion of $\mathrm{CO} 2$ in the soil. 


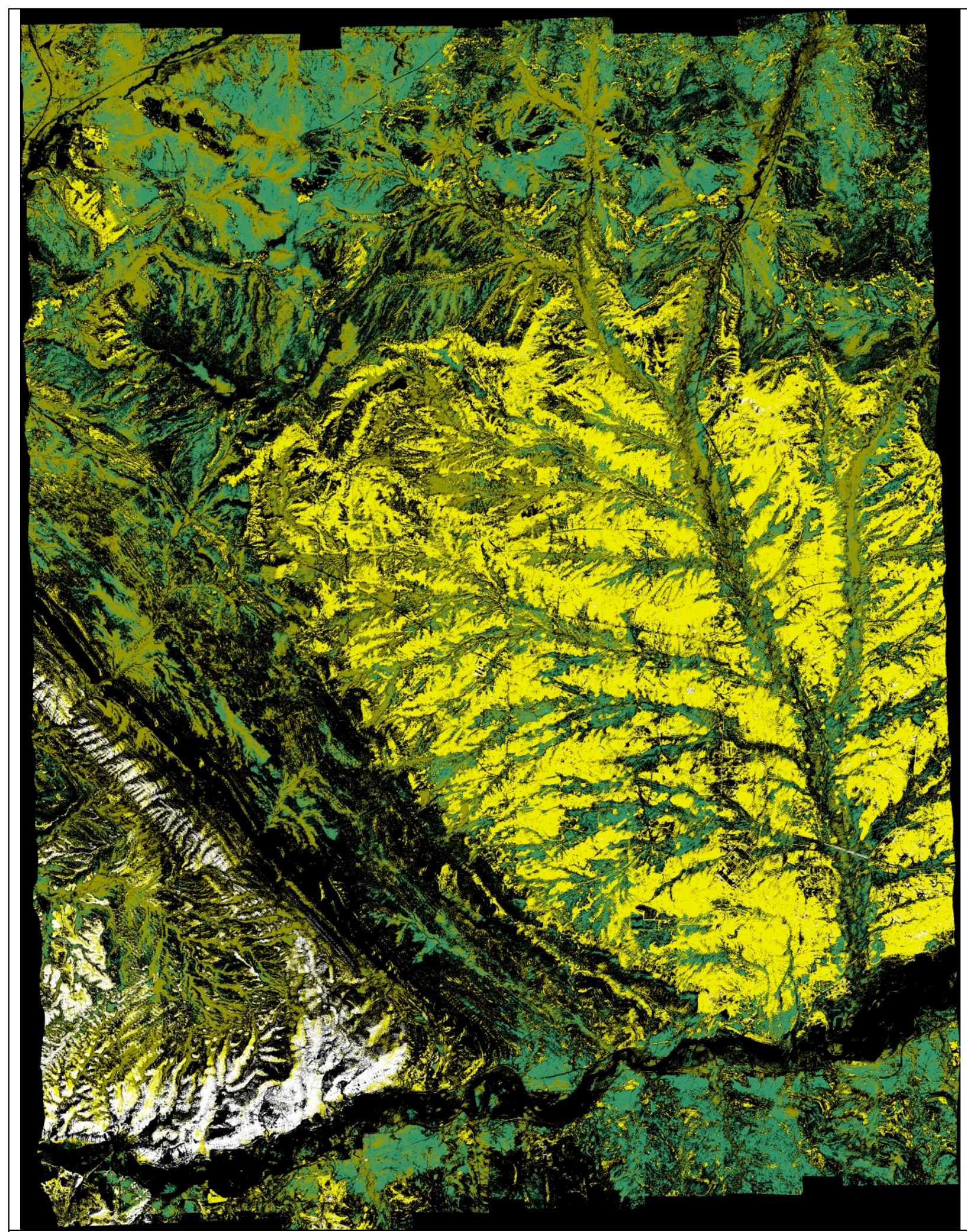

Figure 26 Three distinct habitats (yellow, green, and brown) and a soil type (White) mapped across the entire Rangely region 
We have also begun to make use of the new very high-resolution commercial satellite called QuickBird. It is operated by the Digital Globe Corp. We do have access to the QuickBird imagery worldwide. The panchromatic imagery has a resolution of 0.6 meters, and the for band multispectral imagery spatial resolution is 2.4 meters. Quick Bird has not yet imaged Rangely CO. We would have to task the satellite at a cost of about $\$ 4,000$. The figure below what a QuickBird multispectral image of the Rangely oil field and surrounding areas would look like. This imagery is an orthorectified Airphoto. The town and roads are shown. The areas that established the habitat mapping results are labeled Habitat 1 and Habitat 2 in the upper left. 


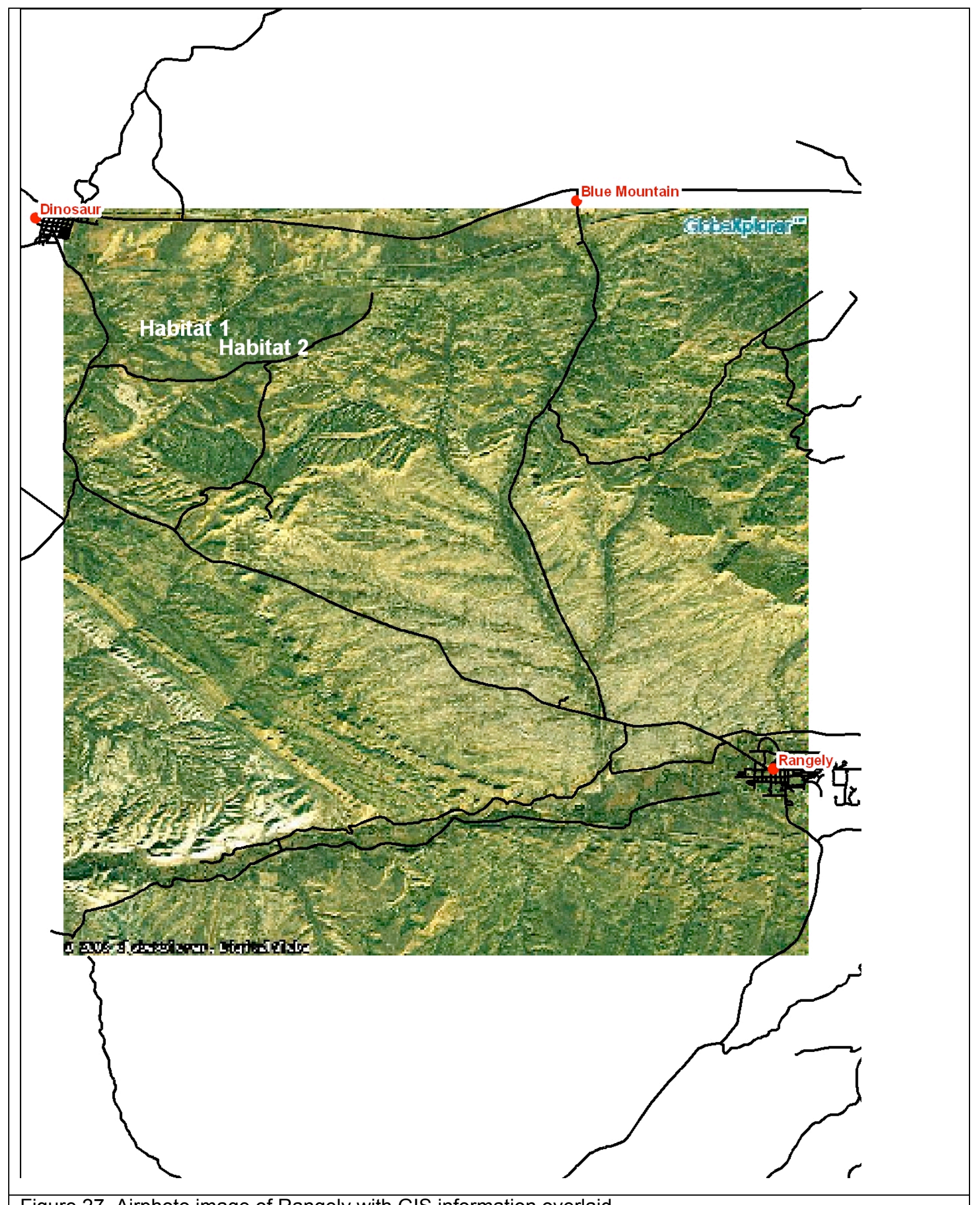

Figure 27 Airphoto image of Rangely with GIS information overlaid 


\section{Conclusions}

In Conclusion, we have found a result that was unexpected, new to us, and potentially very important to the task of monitoring for $\mathrm{CO} 2$ that has leaked to within the plant root depths near the surface. The discovery is that one of our analysis techniques has picked out finely detailed mapping of local ecologies that extend across the entire Rangely oil field and surrounding areas. These ecologies appear to be made up of a fairly narrow range of percentage admixtures of two or three very specific plant types and soil types. We found this result serendipitously by returning to the field at Rangely with all our analysis products and the ENVI program running in our laptop computers. The products are all georectified and so we were able to drive to the exact locations that were being picked out by the analysis and visually inspect them. We were able to walk back and forth between adjacent areas that were being picked out by the analysis. After a while it became apparent what had happened. The computer analysis was sorting out regions based on the relative mixture of plant types, plant sizes, plant spacings, intervening ground cover such as grass types and soils. With in these regions being things like roads, paths, animal trails, manmade objects such as oil well pad areas, tanks, buildings, town, golf courses, are all also apparent and are picked out separately by the algorithm.

The results show incredible, georectified, detail and complexity in the mapping of ecologies, soil types, plant types, plant health, water conditions, and human use features. This work does provide a "snap shot" of the ecological complexity of the entire area as of August 2002. Interestingly we found that the August 2002 imagery analysis seemed to be completely valid in August 2003 during our return field trip. We have not found any evidence in the imagery analysis or anywhere on the ground, during our field trips in August 2002 and august 2003 of any plant life responses that might indicate $\mathrm{CO} 2$ leakage from the formation below. All the excellent and extensive measurements of soil and air concentration levels of $\mathrm{CO} 2$ and Methane made over the last several years made by Ron Klusman, of the Colorado School of Mines under DOE contract, were provided to us by Ron. Ron personally escorted me to many of his sites in August 2002. In our return field trip in August 2003, Wendy Cover and I visited all the sites that Ron identified as potentially above normal in soil $\mathrm{CO} 2$ concentrations. We tried to find anything that we could identify as a biosphere signature of elevated $\mathrm{CO} 2$ soil concentrations. We found nothing at any site we visited. We conclude the "elevated $\mathrm{CO} 2$ and or Methane concentrations" reported by Ron simply are not high enough to have any effect on the biosphere. The "elevated concentrations" might be caused by some trace level seepages from the formations below, but they are not high enough to cause any observable effects on the surface biosphere.

We are still not sure if we have found any evidence at Rangely of what might be subtle hidden

faults that could provide pathways for $\mathrm{CO} 2$ upward migration in the future.

\section{Recommendations}

We strongly recommend a long term research effort that will establish what $\mathrm{CO} 2$ soil concentration levels produce observable changes in the biosphere and the corresponding subtle and complex ecological distributions in various environments (including terrestrial and marine). This is an extremely important and highly relevant task for CCP SMV to pursue in our opinion. The biosphere is always out there, integrating, and responding to and creating changes. We recommend that, as a very important environmental program, we are well advised to learn to read and understand, all the subtle signs it is providing to us, continuously.

We propose that the CCP establish a CO2 effluent, plant effects study Institute, using emission areas at Mammoth Mountain CA and at Green River Utah USA. Using areas of known CO2 effluents, we should establish real time continuous soil and near surface $\mathrm{CO} 2$ concentration recordings. We then need to make periodic, direct metabolic measurements of individual plant health. We suggest that the Institute be operated through the UCSC Center for Remote Sensing. The institute would involve collaboration with the USGS, the DOE geothermal and natural gas 
infra structure reliability programs, the DOE CO2 sequestration Center study site at Teapot Dome, and other Universities It could also be a test-bed for several parts of the larger CCP program needs. It would provide credibility for the CCP by having an operating facility in a public use area with known potential life threatening $\mathrm{CO} 2$ effluents. It would allow studying both dose effects and dose rate effects on different species through all seasons.

We also recommend trying to measure directly $\mathrm{CO} 2$ and $\mathrm{CH} 4$ gas concentrations in the air using airborne hyperspectral imagers. We recommend using infrared hyperspectral imaging spectrometer sensors that have enough wavelength resolution to measure the $\mathrm{CO} 2$ and $\mathrm{CH} 4$ absorbtion ressonances in the infrared that are due to rotational, strech, and vibrational molecular absorbtion mechanisms. The sensors will have to be able to distinguish the $\mathrm{CO} 2$ and $\mathrm{CH} 4$ resonances from other resonannces caused by molecules that are likely to be present in the confuse the measurements. The sensitivity will have to be great enough to measure normal background concentrations in air, so that anomalouies can be detected.

We also recommend starting a program to develop in expensive, nanotechnology sensor to detect $\mathrm{CO} 2$ and $\mathrm{CH} 4$ concentrations in soils and at the surface. New sensors that are unpowered atonomous and read out by pulsed rf or optical interogation during a fly over could be placed along faults, near well head, and at any features thouht to possible venting paths. These would be permenatly installed and readout at what ever interval was required.

\section{Acknowledgements}

This work was performed under the auspices of the U.S. Department of Energy by the University of California, Lawrence Livermore National Laboratory under Contract No. W-7405-Eng-48.

\section{References}

William L. Pickles, U of California LLNL, Gregory D. Nash, U of Utah, Wendy M. Calvin, U of Nevada Reno, Brigette A. Martini, HyVista Corp. Sydney Australia, Peter A. Cocks, HyVista Corp. Sydney Australia, Ty Kenedy-Bowdoin, U of California Santa Cruz, Robert B. Mac Knight IV, U of California Santa Cruz, Eli A. Silver, U of California Santa Cruz, Donald C. Potts, U of California Santa Cruz, William Foxall, U of California LLNL, Paul Kasameyer, U of California LLNL, Geobotanical Remote Sensing Applied to Targeting New Geothermal Resource Locations in the US Basin and Range with a focus on Dixie Meadows NV, Geothermal Resources Council Transactions, Vol. 27, October 12-15, 2003, Geothermal Resources Council, PO Box 1350, Davis California, 95616, USA, UCRL-JC-153443

B.A. Martini ${ }^{1}$, E.A. Silver ${ }^{2}$, W.L. Pickles ${ }^{3}$, P.A. Cocks ${ }^{1}$, Hyperspectral Mineral Mapping in Support of Geothermal Exploration: Examples from Long Caldera, CA and Dixie Valley, NV, USA ${ }^{1}$ HyVista Corporation, Sydney, NSW, 2113, Australia, ${ }^{2}$ UCSC Earth Sciences, Santa Cruz, CA, USA, 95064, ${ }^{3}$ Lawrence Livermore National Laboratory, Livermore, CA, USA, 95007, Geothermal Resources Council Transactions, Vol. 27, October 12-15, 2003, Geothermal Resources Council, PO Box 1350, Davis California, 95616, USA

Brigette A. Martini, NEW INSIGHTS INTO THE STRUCTURAL, HYDROTHERMAL, AND BIOLOGICAL SYSTEMS OF LONG VALLEY CALDERA USING HYPERSPECTRAL IMAGING, A dissertation submitted in partial satisfaction of the requirements for the degree of DOCTOR OF PHILOSOPHY in EARTH SCIENCES, UC Santa Cruz, December 2002 http://eed.IInl.gov/other/martini/

Brigette A. Martini thesis chapter 3 and 4 are found at: Hyperspectral Imaging in Long Valley Caldera: Volcano-associated Biological Communities http://eed.Ilnl.gov/other/martini/chapter3.pdf http://eed.IInl.gov/other/martini/Ch3 Figures.pdf 
Hyperspectral Imaging in Long Valley Caldera: Tracking volcanogenic $\mathrm{CO}_{2}$ and its lethal effects http://eed.Ilnl.gov/other/martini/chapter4.pdf

http://eed.Ilnl.gov/other/martini/Ch4 Figures.pdf

McGee, KA, and Gerlach, TM, 1998, Annual cycle of Magmatic CO2 at Mammoth Mountain, California: Implications for soil acidification: Geology, v. 26, p. 463-466

Rogie, JD et al., 2001, Dynamics of carbon dioxide emission at Mammoth Mountain, California, EPSL, v. 188 , p. $535-541$

Cook, AC et al., 2001, Radiocarbon studies of plant leaves and tree rings from Mammoth Mountain, CA: a long-term record of magmatic CO2 release, Chemical Geology, v. 177, p. 117131

Bergfeld, D. et al., 2001, Elevated carbon dioxide flux at the Dixie Valley geothermal field, Nevada; relations between surface phenomena and the geothermal reservoir, Chemical Geology, v. 177 , p. $43-66$

Response of Soil Mineral Weathering to Elevated CO2, Jennie C. Stephens, Ph. D. Thesis, California Institute of Technology, 2002

Cocks, T.D., R. Jenssen, A. Stewart, I. Wilson, T. Shields, 1999, The HyMap Airborne Hyperspectral Sensor: The System, Calibration and Performance, Proceedings of 1st EARSEL Workshop on Imaging Spectroscopy, Zuri

Carbon Dioxide and Environmental Stress, Yigi Luo, DRI Reno NV USA, and Harold A. Mooney, Stanford University, CA USA Academic Press, 1999, Library of Congress 99-600087

Larcher, W. 1995. Physiological Plant Ecology, Third Edition. Springer-Verlag, New York.

The Carbon Dioxide Dilemma: Promising Technologies and Policies http://www.nap.edu/catalog/10798.html?do se92

Living on an Active Earth: Perspectives on Earthquake Science http://www.nap.edu/catalog/10493.html?do se92

William L. Pickles, Geobotanical hyperspectral remote sensing of Vegetation Responses to CO2 Leakage

From Underground storage formations, CCP SMV International Meeting, GFZ, Potsdam,

Germany,

October 31, 2001

William L. Pickles, Finding hidden faults above and Vegetation Responses to CO2 Leakage from Underground storage formations, CCP SMV International Meeting, University of California Santa Cruz,

October 21, 2002,

William L. Pickles, LLNL, Wendy A. Cover, UCSC, Donald C. Potts, UCSC, Brigette A Martini, Hyvista Corp, Possible CO2 Leakage Monitoring and Verification. Finely Detailed Habitat Mapping Using High Resolution Hyperspectral Imagery At the Rangely CO, USA, EOR field, CCP SMV International Meeting in Dublin Ireland,

September 21, 2003 
William L. Pickles, Hyperspectral Geobotanical Remote Sensing for CO2 Storage Monitoring, $\mathrm{CO}_{2}$ Capture Project - An Integrated, Collaborative Technology Development Project for Next Generation $\mathrm{CO}_{2}$ Separation, Capture and Geologic Sequestration, Semi-Annual Report, 2.4.4, July 14,2003

We have many references that relate all our hyperspectral remote sensing programs with other hyperspectral programs worldwide. It is best to visit our website where many of these can be viewed and or downloaded for your use. Our site is http://emerald.ucsc.edu/ hyperwww/instruments.html

There is also a remote sensing tutorial developed for and funded by Dr. Lucinda Jackson at ChevronTexaco, Richmond CA. Please visit this website, which is a version that is open to the public. http://es.ucsc.edu/ hyperwww/chevron/

\section{Other Background References}

"Hyperspectral Remote Sensing for Research and Monitoring in Active Volcanic Regions", B. A. Martini, E. A. Silver, W. L. Pickles, American Geophysical Union (AGU), San Francisco, paper V22F-05, December, 2000

"Use of hyperspectral sensing to obtain micro-scale ecological data on meso- to macro-scales", Potts, D.C., Siciliano, D., Martini, B.A., Pickles, W.L. Silver, E.A., $9^{\text {th }}$ Intl. Coral Reef Symp., 2000 "Hyperspectral applications across land-sea gradients from open ocean to watershed uplands", Siciliano,D., Potts, D.C., Martini, B.A., Pickles, W.L., Silver, E.A., IEEE 2000 Intl. Geosci. Remote Sens. Symp., 2000

"High resolution hyperspectral sensing as an environmental monitoring tool for coastal and shallow marine habitats", Siciliano, D., Potts, D., Marini, B., Silver, E., Pickles, W., $6^{\text {th }}$ Intl. Conf. Remote Sens. Mar. Coast. Envir. [Best Paper Award], 2000

"Geological and Geobotanical Characterization of a Hydrothermal System Using Hyperspectral Imagery Analysis", ERIM, Summer Meeting, Vancouver BC, B. A. Martini, S. A. Cochran, E. A. Silver, W. L. Pickles, D.C. Potts, July 1999

"New hyperspectral remote sensing techniques using geobotany, geology, and gas emission observations, for applied geothermal exploration and exploitation", Martini, B.A., Cochran, S.A., Potts, D.C., Silver, E.A., Pickles, W.L., Carter, M.R., Priest, R.E., Wayne, B.M., White, W.T., Anderson, T., $13^{\text {th }}$ Intl. Conf. Appl. Geol. Remote Sens., 1999

"Geological and Geobotanical Studies of Long Valley Caldera and Mammoth Mountain CA Utilizing New High Resolution Hyperspectral Imagery", EOS, Fall AGU Meeting, San Francisco, CA, B.A Martini, Eli. A. Silver, W. L. Pickles, D. C. Potts, 1999

"Mapping environmental stress in Elkhorn Slough, central California using hyperspectral data: a management tool for an at-risk coastal ecosystem", Cochran, S.A., Martini, B.A., Jacobs, J.R., Potts, D.C., Silver, E.A., Pickles, W.L., $5^{\text {th }}$ Intl. Conf. Remote Sens. Mar. Coast. Envir., 1998

"Geological and Geobotanical Characterization of Hydrothermal System Utilizing Hyperspectral Imagery Analysis", EOS, Fall AGU Meeting, San Francisco, CA, B.A Martini, S. A. Cochran, Eli. A. Silver, W. L. Pickles, D. C. Potts, 1998

"Detecting Plant Metabolic Responses Induced by Ground Shock Using Hyperspectral Remote Sensing and Physiological Contact Measurements", W. L. Pickles, G. A. Carter, UCRL-ID127061, December 3, 1996 
"Observations of Temporary Plant Stress Induced by the Surface Shock of a 1-Kt Underground Explosion”, William L. Pickles, UCRL-ID-122557, December 4, 1995, available through National Technical Information Service, U.S. Dept of Commerce, Springfield, VA 22161

"Low Altitude Overhead Imagery Acquisition Pre-and Post-NPE", William L. Pickles, LLNL, Janet E. Shines, David L. Hawley, Michael D. Pelan, and Stanley B. Brewster, Jr., EGG RSL,

Proceedings of the Symposium on the Non-Proliferation Experiment: Results and Implications for Test Ban Treaties, pages 8-63 through 8-70, CONF 9404100, April 19-21, 1994

\title{
List of Acronyms and Abbreviations
}

\author{
FOV field of view \\ GPS Global Positioning System \\ DGPS differential GPS using the two GPS designated satellites for reference \\ IMU inertial monitoring unit \\ GIFOV ground field of view nominal \\ $\mathrm{mr} \quad$ mili-radians of angular view \\ LLNL Lawrence Livermore National Laboratory \\ UCSC University of California Santa Cruz \\ EOR Enhanced Oil Recovery (field) \\ CO2 Carbon Dioxide
}

\section{Tables \& Figures}

Figure 1 At Mammoth Mountain CO2 Emission levels burst on short time scales to hazardous levels in small areas

Figure 2 Trees killed at Mammoth Mountain CA by highly elevated CO2 soil concentrations. This area is near Horseshow Lake

Figure 3 Tree health from hyperspectral imagery Blue unhealthy, Green intermediate, Red healthy

Figure 4 Plant health mapping from hyperspectral imagery

Figure 5 Hidden faults, mineralization and tree kill mapping from the hyperspectral imagery at Mammoth

Figure 6 Wendy Cover using the ASD field spectroradiometer to measure reflectance spectra at Rangely in August 2003. The spectrometer is in the backpack. The computer that controls the spectrometer and displays the acquired spectra is in a front pack sling. The pistol grip lens that is connected to the spectrometer by a fiber optic cable, is in her right hand.

Figure 7 Morning preparations of the B 300 Twin Otter aircraft rented by HyVista. The LLNL UCSC team meets with the HyVista team while they are preparing the Hymap sensor, the georectification system, and computer system for the hyperspectral image acquisition. Note the clear skies, which is ideal

Figure 8. The hyperspectral sensor is shown in the aircraft used by our acquisition contractor for image acquisitions

Figure 9. Ashley Hill is the acquisition contractor's sensor operator and flight commander. He is shown with the onboard computer system that controls the sensor systems and records the 
image, and the exact geolocation of each pixel in the image as it is acquired. The aircraft is the B300 Twin Otter.

Figure 10 This is a digital elevation model of the Rangely Oil Field basin and surrounding formations with flightlines.

Figure 11 All the flight lines used to make a "true color" RGB image of the whole Rangely Oil Field basin, the surrounding formations and the town of Rangely.

Figure 12 All the flight lines images converted to NDVI images and mosiaced. This is a gray scale image. The whiteness or brightness of each image pixel means both that there is a higher percentage of plant coverage in the pixel area and or that the plants are exposing more chlorophyll in their leaves and stems.

Figure 13 NDVI line 12A left, 12B right

Figure 14 View of the Rangely oil field south of Mellen Hill.

\begin{tabular}{|l|l|}
\hline $\begin{array}{l}\text { Figure 15 } \\
\text { Unsupervised }\end{array}$ & $\begin{array}{l}\text { Minimum Noise Fraction } \\
(\mathrm{MNF})\end{array}$ \\
\hline
\end{tabular}

Figure 16 Detailed habitat mapping that results from an ENVI "hourglass" process. This process ended with a Spectral Angle Mapper (SAM) analysis of flightline11 that is shown in the center. On the left is a "true color" RGB image of flightline 11

Figure 17 Habitat mapping using flight line 3 hyperspectral image. True color (15,9,2 RGB) on right, Infrared is in center, SAM Habitats on the right.

Figure 18 Close up of line 3 SAM analysis showing the newly discovered habitats

Figure 19 Continous recording of our handheld DGPS during one day of the July 2003 field trip showing the sites visited that established "habitat" mapping concept.

Figure 20 Closeup view of the location of the area where we discovered that the SAM analysis was mapping "habitats". The DGPS waypoints acquired while walking the habitat picked by the SAM analysis of the line 3 hyperspectral image are shown as the group of red dots at the top center. The other red dots on the roads to the northeast (upper right) were places mapped by the SAM analysis as the same habitat types. We drove to these sites guided by our georectified SAM imagery analysis and found they were indeed the same type habitats. Once we became educated about we began to recognize these habitats at many places.

Figure 21 The two adjacent habitats discovered by using the line 3 SAM analysis categories.

Figure 22 Wendy Cover measuring reflectance spectra of a plant at the border between two habitats. Notice the well pad and our SUV "mobile office" which had the laptop running with her SAM results.

Figure 23 The red dots are DGPS waypoints collected by walking the perimeter of the habitat shown in the top half of figure 20. The DGPS points are shown overlaid on the 1990 airphoto.

Figure 24 Northern boundary of habitat and the next habitat of Junipers. The edge is accurately mapped by SAM analyisis and the DGPS waypoints (red dots)

Figure 25 Closeup of the northern boundary between habitats. This is the top if the "finger" in the top of the DGPS waypoints (red dots) shown in figure 22. 
Figure 26 Three distinct habitats (yellow, green, and brown) and a soil type (White) mapped across the entire Rangely region

Figure 27 Airphoto image of Rangely with GIS information overlaid 